Argonne

Neutronic, Steady-State, and Transient Analyses for the Kazakhstan VVR-K Reactor with LEU Fuel:

ANL Independent Verification Results

Nuclear Engineering Division 


\section{About Argonne National Laboratory}

Argonne is a U.S. Department of Energy laboratory managed by UChicago Argonne, LLC

under contract DE-AC02-06CH11357. The Laboratory's main facility is outside Chicago, at 9700 South Cass Avenue, Argonne, Illinois 60439. For information about Argonne

and its pioneering science and technology programs, see www.anl.gov.

\section{DOCUMENT AVAILABILITY}

Online Access: U.S. Department of Energy (DOE) reports produced after 1991 and a growing number of pre-1991 documents are available free via DOE's SciTech Connect (http://www.osti.gov/scitech/)

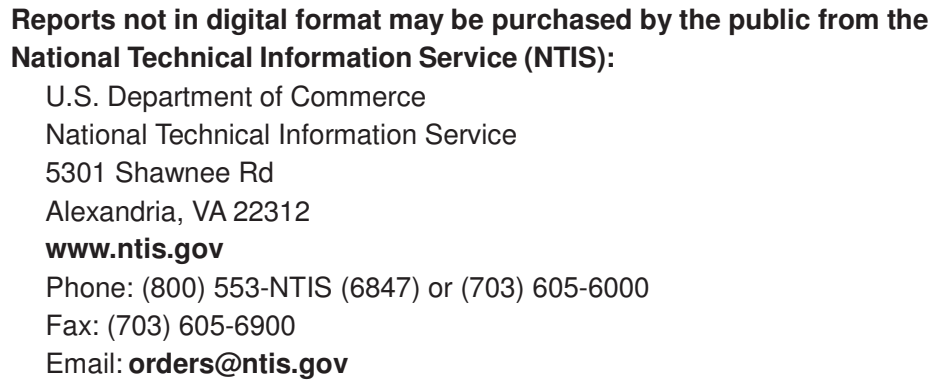

Reports not in digital format are available to DOE and DOE contractors from the Office of Scientific and Technical Information (OSTI):

U.S. Department of Energy

Office of Scientific and Technical Information

P.O. Box 62

Oak Ridge, TN 37831-0062

www.osti.gov

Phone: (865) 576-8401

Fax: (865) 576-5728

Email: reports@osti.gov

\section{Disclaimer}

This report was prepared as an account of work sponsored by an agency of the United States Government. Neither the United States Government nor any agency thereof, nor UChicago Argonne, LLC, nor any of their employees or officers, makes any warranty, express or implied, or assumes any legal liability or responsibility for the accuracy, completeness, or usefulness of any information, apparatus, product, or process disclosed, or represents that its use would not infringe privately owned rights. Reference herein to any specific commercial product, process, or service by trade name, trademark, manufacturer, or otherwise, does not necessarily constitute or imply its endorsement, recommendation, or favoring by the United States Government or any agency thereof. The views and opinions of document authors expressed herein do not necessarily state or reflect those of the United States Government or any agency thereof, Argonne National Laboratory, or UChicago Argonne, LLC. 


\section{Neutronic, Steady-State, and Transient Analyses for the Kazakhstan VVR-K Reactor with LEU Fuel:}

ANL Independent Verification Results

prepared by

N. A. Hanan and P.L. Garner

Nuclear Engineering Division, Argonne National Laboratory

sponsored by

U. S. Department of Energy, National Nuclear Security Administration

Office of Material Management and Minimization

August 2015 



\title{
Neutronic, Steady-State, and Transient Analyses for the Kazakhstan VVR-K Reactor with LEU Fuel: ANL Independent Verification Results
}

\author{
N. A. Hanan and P.L. Garner \\ Research and Test Reactor Department \\ Nuclear Engineering Division \\ Argonne National Laboratory \\ 9700 South Cass Avenue, Lemont, 60439, Illinois - USA \\ August 2015
}

\section{Summary}

Calculations have been performed for steady state and postulated transients in the VVR-K reactor at the Institute of Nuclear Physics (INP), Kazakhstan. (The reactor designation in Cyrillic is BBP-K; transliterating characters to English gives VVR-K but translating words gives WWR-K.) These calculations have been performed at the request of staff of the INP who are performing similar calculations. The selection of the transients considered started during working meetings and email correspondence between Argonne National Laboratory (ANL) and INP staff. In the end the transients were defined by the INP staff. Calculations were performed for the fresh low-enriched uranium (LEU) core and for four subsequent cores as beryllium is added to maintain criticality during the first 15 cycles. These calculations have been performed independently from those being performed by INP and serve as one step in the verification process. 


\section{Reactor Information}

\subsection{General}

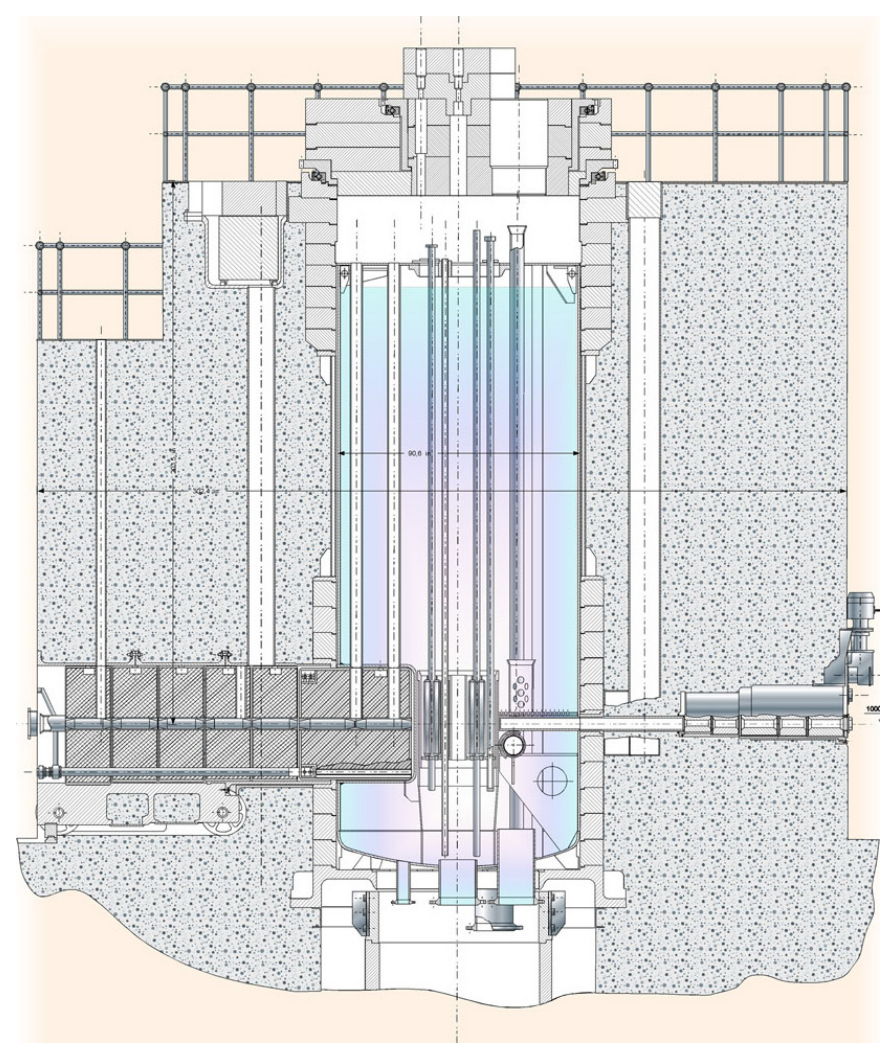

Figure 2.1.1 VVR-K Elevation View [1]
The VVR-K reactor is located at the INP in Alatau. It is a pool type reactor. An elevation schematic of the reactor is shown in Figure 2.1.1. The core is located in a cylindrical reactor vessel, having inner diameter of $2.3 \mathrm{~m}$ and water level height of $5.3 \mathrm{~m}$. The design thermal power is $10 \mathrm{MW}$; the permitted power is $6 \mathrm{MW}$. The core is cooled by forced convection of light water; the water enters the bottom of the central tank through a single $0.35 \mathrm{~m}$ diameter pipe, flows upward, turns toward the center and flows down through the core, exiting the center of the reactor vessel through a single $0.35 \mathrm{~m}$ diameter pipe. 


\subsection{HEU Fuel}

Although this report includes no analysis for the current High Enriched Uranium (HEU) fuel core, the Fuel Assembly (FA) geometries are shown below in Figure 2.2.1 in order to provide some perspective on the LEU FA. The hexagonal FA have either 5 tubular Fuel Elements (FE) or 3 FE plus a central space for a control rod (CR) The fuel meat is $1 \mathrm{~mm}$ thick with $0.65 \mathrm{~mm}$ of cladding on each side.

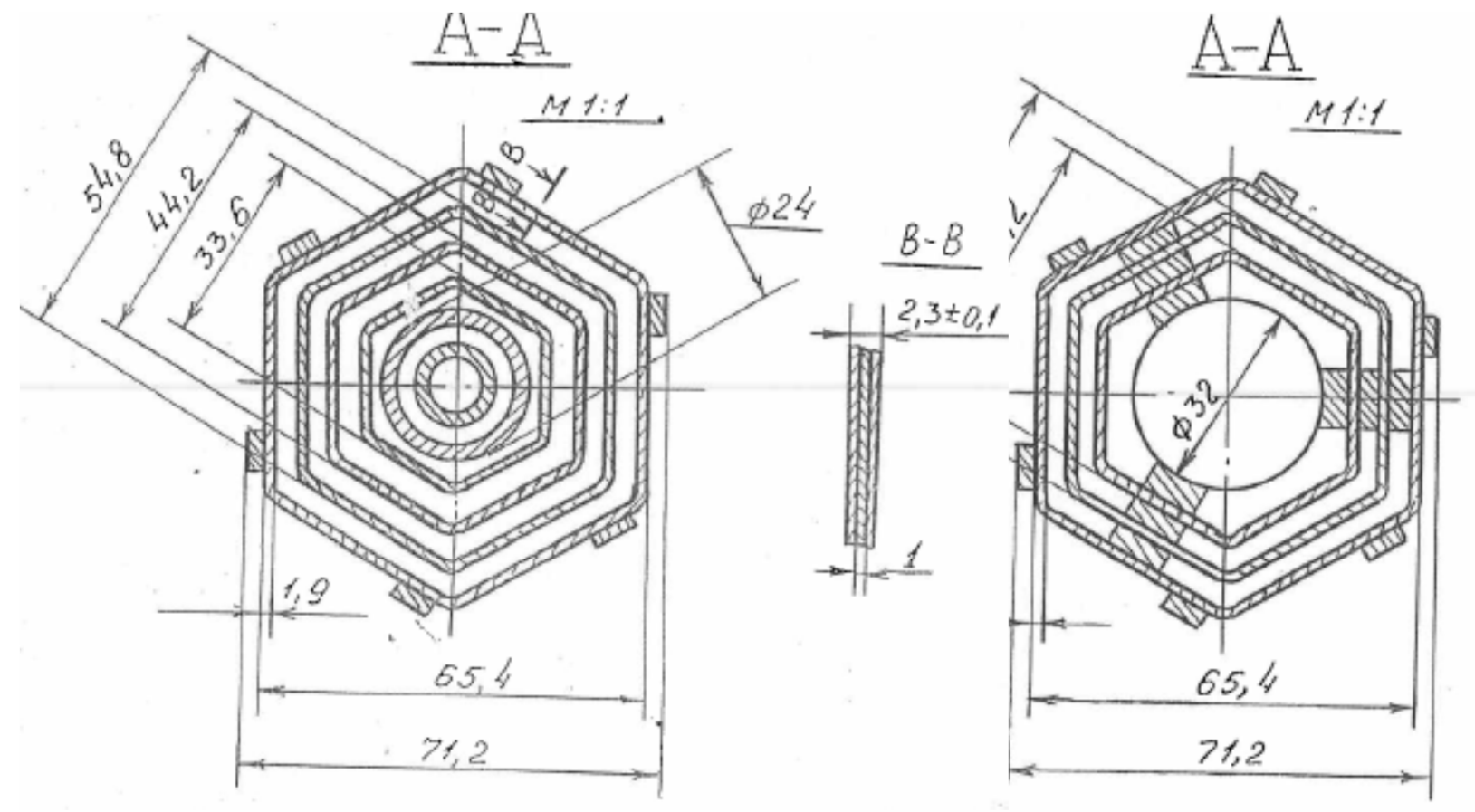

Figure 2.2.1 HEU Fuel Assembly Geometry [2] 


\subsection{LEU Fuel}

There are two types of LEU FA denoted VVR-KN. Type FA-1 has 7 concentric tubular fuel elements (FE) of hexagonal cross section and an 8-th central cylindrical FE. There is a cylindrical structural tube interior to the 8-th FE. Type FA-2 has the same outermost 5 concentric tubular FE as in FA-1; interior to the FE is a cylindrical guide tube for Control Rod (CR). Dimensions are shown below in Figure 2.3.1. Corner rounding is $6.9 \mathrm{~mm}$ radius for outside of outermost $\mathrm{FE}$, decreases by $0.4 \mathrm{~mm}$ for each tube moving inward; inner corner rounding is $1.6 \mathrm{~mm}$ less than outer corner rounding for each FE. The ribs are actually trapezoid shape rather than the half circle implied by dimension "R1.5" in figure.
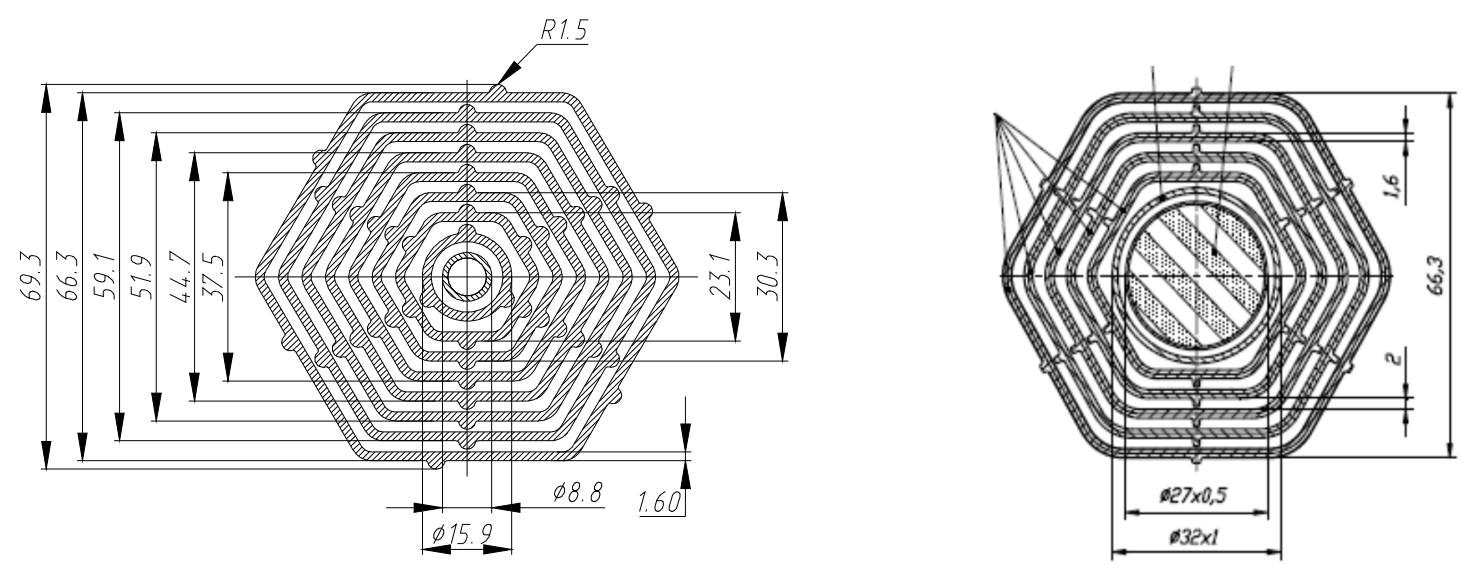

Figure 2.3.1 LEU Fuel Assembly Geometry [1] (FA-1 on left, FA-2 on right.)

The FEs are $1.6 \mathrm{~mm}$ thick, consisting of $0.7 \mathrm{~mm}$ of fuel meat and $0.45 \mathrm{~mm}$ of cladding on each side. The fuel meat is $\mathrm{UO}_{2}-\mathrm{Al}$, enriched to $19.75 \%$ in $\mathrm{U}-235$. The U-235 masses are $248.2 \mathrm{~g}$ in FA-1 and $197.6 \mathrm{~g}$ in FA-2; this yields a mean fuel density of about $2.8 \mathrm{~g} / \mathrm{cm}^{3}$ of uranium. Cladding and other structural items are made of the aluminum-alloy SAV-1. Ribs of height $1.5 \mathrm{~mm}$ provide stiffening of FE and help maintain $2 \mathrm{~mm}$ water gap between adjacent FE. The design of fuel meat is $0.6 \mathrm{~m}$ in length with a standard deviation of $0.002 \mathrm{~m}$. In the analyses presented in this report the nominal dimensions and masses of the fuel were used. 


\subsection{Core Descriptions}

The initial critical configuration is achieved by loading a few LEU FA then performing measurements to assess the neutron multiplication factor $\left(k_{\text {eff }}\right)$. Criticality is achieved when multiplication factor reaches 1.0. INP has provided ANL with the intended order for loading FA [3]. This is shown in the left column of Table 2.4.1 using numbering pattern shown in Figure 2.4.1. The FA-2 are loaded first, since each contains a CR. During the early stages of loading more than one FA can be loaded between measurement points. Calculations using MCNP [4] predict that criticality will be achieved with 10 FA-2 and 11 FA-1. All neutronics calculations in this report were performed using MCNP6 and ENDF/B-VII.0 cross sections. INP will continue loading FA-1 to reach "work load" core having 10 FA-2 and 17 FA-1.

Table 2.4.1: Progression of Core Loading

\begin{tabular}{|c|c|c|}
\hline Core Position & FA-2 + FA-1 Count & $\mathrm{k}_{\text {eff }^{\mathrm{a}}}$ \\
\hline \multicolumn{3}{|l|}{$7-3(1 A Z)$} \\
\hline \multicolumn{3}{|l|}{$9-4(2 A Z)$} \\
\hline $5-8(3 A Z)$ & $3+0$ & 0.3597 \\
\hline \multicolumn{3}{|l|}{$4-6(2 \mathrm{KO})$} \\
\hline \multicolumn{3}{|l|}{$6-3(3 \mathrm{KO})$} \\
\hline $8-6(6 \mathrm{KO})$ & $6+0$ & 0.4826 \\
\hline \multicolumn{3}{|l|}{$7-8(4 \mathrm{KO})$} \\
\hline \multicolumn{3}{|l|}{ 4-3 (1KO) } \\
\hline $8-3(5 \mathrm{KO})$ & $9+0$ & 0.5993 \\
\hline $3-4(A R)$ & $10+0$ & 0.6104 \\
\hline \multicolumn{3}{|l|}{$6-5$} \\
\hline $7-6$ & $10+2$ & 0.7216 \\
\hline \multicolumn{3}{|l|}{$6-4$} \\
\hline $5-6$ & $10+4$ & 0.8275 \\
\hline \multicolumn{3}{|l|}{$7-4$} \\
\hline $5-4$ & $10+6$ & 0.8961 \\
\hline \multicolumn{3}{|l|}{$5-7$} \\
\hline $6-7$ & $10+8$ & 0.9391 \\
\hline $4-5$ & $10+9$ & 0.9672 \\
\hline $8-4$ & $10+10$ & 0.9892 \\
\hline 8-5 & $10+11$ & 1.0078 - Critical \\
\hline $7-7$ & $10+12$ & 1.0255 \\
\hline $4-7$ & $10+13$ & 1.0347 \\
\hline $4-4$ & $10+14$ & 1.0490 \\
\hline $5-3$ & $10+15$ & 1.0593 \\
\hline $8-7$ & $10+16$ & 1.0678 \\
\hline $9-3$ & $10+17$ & 1.0765 - Working Load \\
\hline
\end{tabular}

a: Standard deviation less than $1.0 \mathrm{e}-5$ for all calculations.

Figure 2.4.1 shows the several LEU core configurations to be used. Legend for hexagons: grey-shaded is FA-1; grey-shaded with white interior circle is FA-2 with CR identifier ( $n K O, n A Z$, or AR) noted; white is water displacer; white with interior circle is irradiation position; blue diagonal lines indicate beryllium. 
In upper left is the initial critical configuration: 10 FA-2 plus 11 FA-1. In upper right is the initial work load core: 10 FA-2 plus 17 FA-1. After three cycles of operation calculations using MC-REBUS [5-6] and MCNP indicate that the excess reactivity will have dropped sufficiently low as to be unable to sustain criticality. At that time INP will replace water-displacer blocks with beryllium blocks (Be) outside of the FA locations to reflect neutrons back into the core. Additional Be will be added after cycles 9, 11, and 14; these cores are shown in middle left, middle right, bottom left, and bottom right, respectively, in Figure 2.4.1. The order in which Be are added was provided by INP and is shown in Table 2.4.2. The necessity of adding the Be is shown in Figure 2.4.2, which plots excess reactivity versus full power days; additional Be must be added if the excess reactivity is projected to be between 0 and 1 at the end of the defined 20 day cycle length.

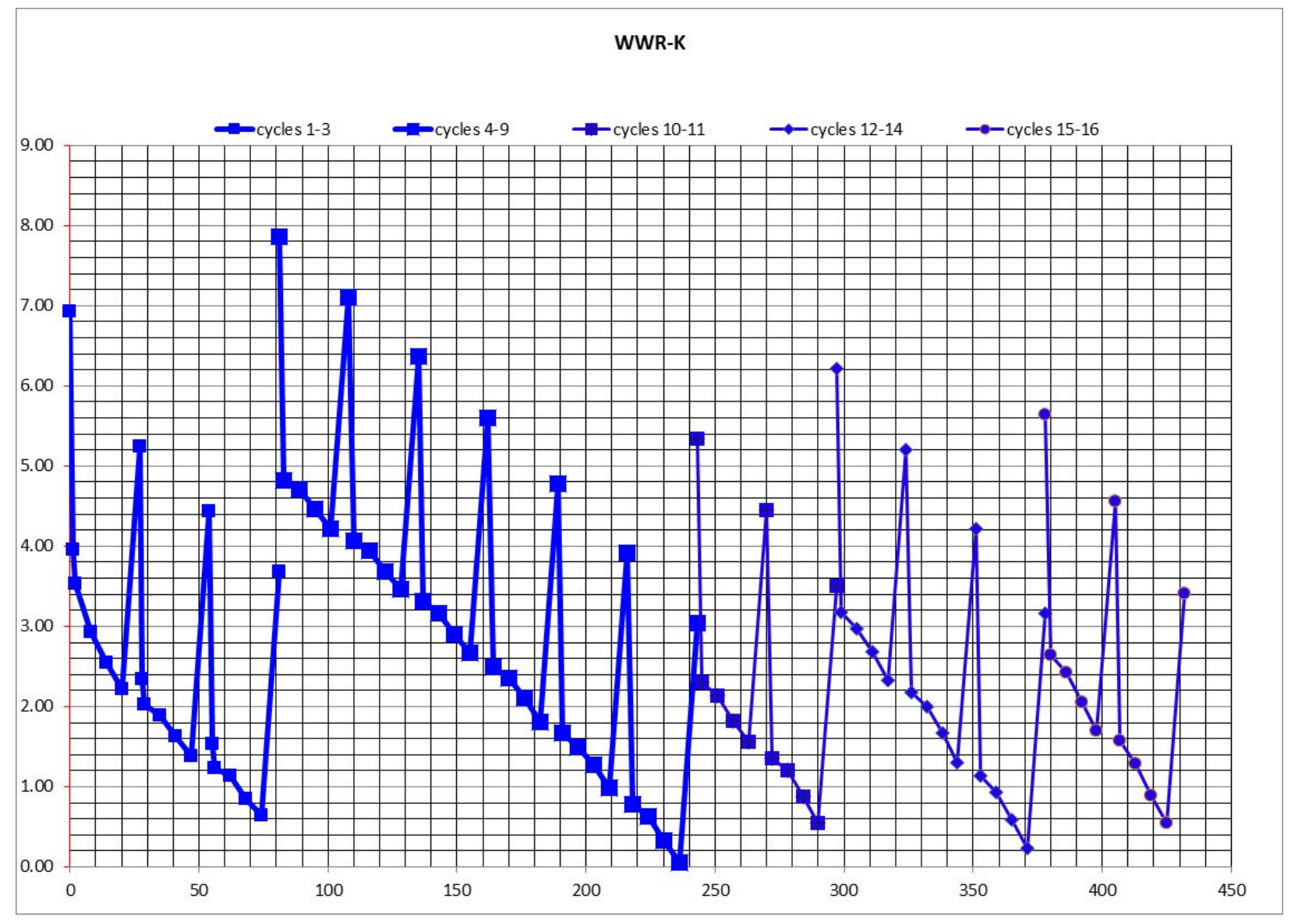

Figure 2.4.2 Change in excess reactivity [\%] versus time [full power days]

Table 2.4.2 Order of Adding Beryllium to Core

\begin{tabular}{|c|c|c|}
\hline Cycles & Core ID & Core Locations for Adding Be Assemblies \\
\hline $1-3$ & $10+17+0 \mathrm{Be}$ & none \\
\hline $4-9$ & $10+17+10 \mathrm{Be}$ & $3-2,3-3,2-3,3-6,4-8,6-8,9-5,9-6,10-3,9-2$ \\
\hline $10-11$ & $10+17+16 \mathrm{Be}$ & $2-4,3-5,4-2,3-7,9-7,10-4$ \\
\hline $12-14$ & $10+17+23 \mathrm{Be}$ & $5-9,7-9,8-8,8-2,7-2,6-2,5-2$ \\
\hline 15 and up & $10+17+49 \mathrm{Be}$ & $\begin{array}{l}1-2,1-3,1-4,2-5,2-7,3-8,4-9,5-10,6-9,7-10,9-8,10-7,11-1,11-2, \\
11-3,11-4,7-1,8-1,9-1,10-1,6-1,5-1,4-1,3-1,2-1,10-5\end{array}$ \\
\hline
\end{tabular}



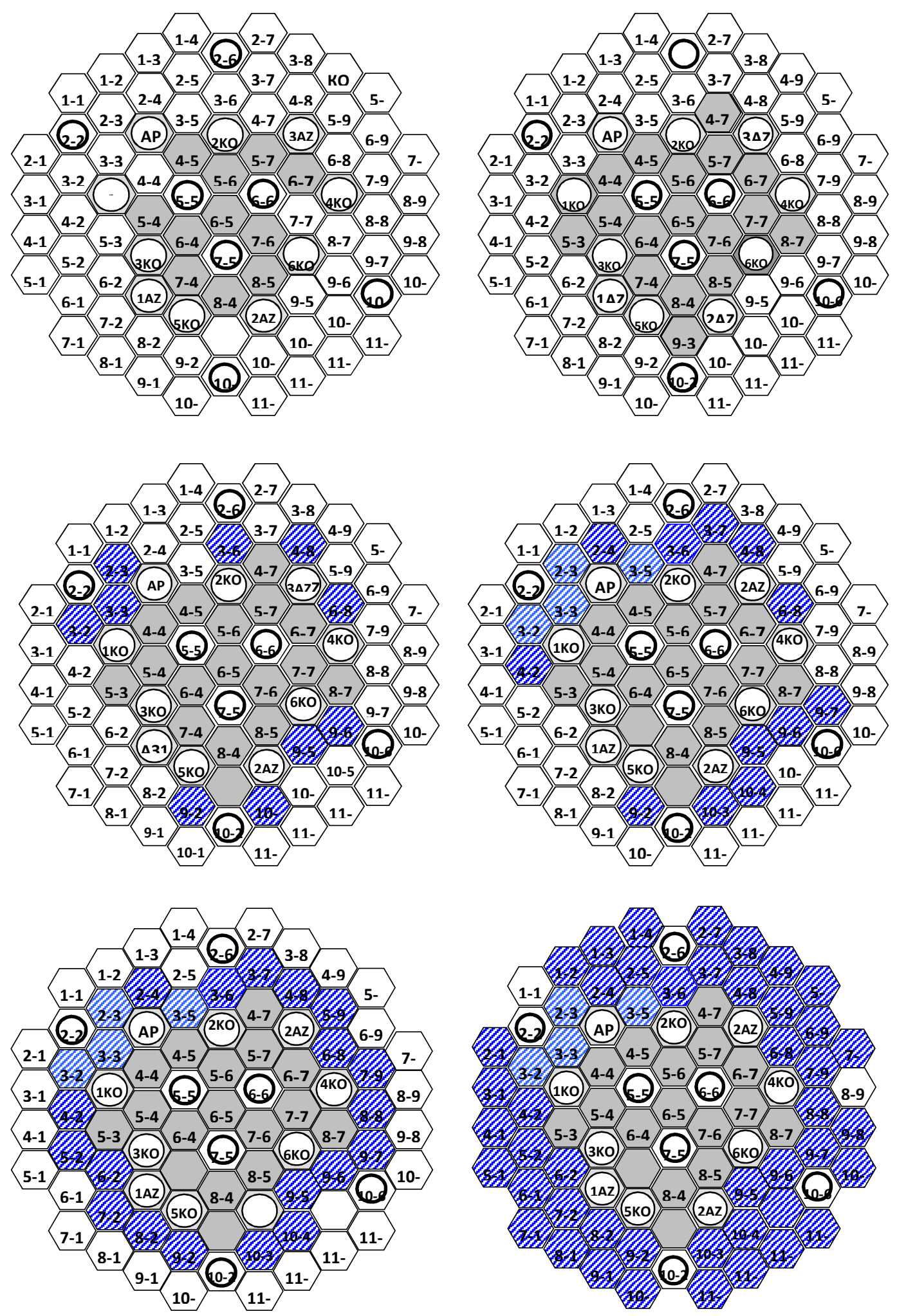

Figure 4.2.1 LEU Core Configurations (See text for explanations.) 


\subsection{Neutronic Parameters}

In order to prepare for transient analysis, various contributions to reactivity change and other neutronics kinetics parameters must be calculated for each core.

The delayed neutron fraction $[\beta(i)]$ and decay constant $[\lambda(i)]$ for 6 groups plus effective delayed neutron fraction ( $\beta$ eff) and prompt neutron generation time $(\Lambda)$ are shown in Table 2.5.1. There is little shift in the group-wise delayed neutron fractions and decay constants during the first 15 cycles. The effective delayed neutron fraction decreases by about $10 \%$. The prompt neutron generation time increases by about $50 \%$ due to addition of the Be reflector.

Table 2.5.1: Delayed Neutron Fractions, Decay Constants, and Prompt Neutron Lifetime

\begin{tabular}{|c|c|c|c|c|c|}
\hline Core: & $10+17+0^{a}$ & $10+17+10$ & $10+17+16$ & $10+17+23$ & $10+17+49$ \\
\hline Cycle: & 1 & 4 & 10 & 12 & 15 \\
\hline$\beta(1)$ & 0.03385 & 0.03605 & 0.03347 & 0.03492 & 0.03179 \\
\hline$\beta(2)$ & 0.16276 & 0.16155 & 0.16876 & 0.16480 & 0.16474 \\
\hline$\beta(3)$ & 0.16016 & 0.16288 & 0.15900 & 0.16061 & 0.16329 \\
\hline$\beta(4)$ & 0.45703 & 0.44993 & 0.46583 & 0.45670 & 0.46098 \\
\hline$\beta(5)$ & \begin{tabular}{|l|}
0.13802 \\
\end{tabular} & 0.13752 & 0.12971 & 0.13408 & 0.13295 \\
\hline$\beta(6)$ & 0.04818 & 0.05207 & 0.04324 & 0.04888 & 0.04624 \\
\hline$\beta \_$eff & 0.00768 & 0.00749 & 0.00717 & 0.00716 & 0.00692 \\
\hline$\lambda(1)[1 / s]$ & 0.01249 & 0.01249 & 0.01249 & 0.01249 & 0.01249 \\
\hline$\lambda(2)[1 / s]$ & 0.03181 & 0.03179 & 0.03176 & 0.03175 & 0.03173 \\
\hline$\lambda(3)[1 / s]$ & 0.10946 & 0.10945 & 0.10943 & 0.10943 & 0.10942 \\
\hline$\lambda(4)[1 / s]$ & 0.31739 & 0.31740 & 0.31740 & 0.31740 & 0.31740 \\
\hline$\lambda(5)[1 / s]$ & 1.35298 & 1.35293 & 1.35229 & 1.35184 & 1.35077 \\
\hline$\lambda(6)[1 / s]$ & 8.66508 & 8.66943 & 8.67023 & 8.66765 & 8.65962 \\
\hline$\Lambda[\mu \mathrm{s}]$ & 46.7 & 50.6 & 57.0 & 60.6 & 69.7 \\
\hline
\end{tabular}

a. Nomenclature " $10+17+0$ " is abbreviation for core having 10 FA-2 plus 17 FA-1 plus 0 Be.

b. Standard deviation $<3.0 \mathrm{e}-5$ for delayed neutron fraction and $<1 \mu \mathrm{s}$ for lifetime.

There are three types of control rods (CR): (1) There are 3 safety rods (AZ1 through AZ3); these are fully withdrawn from the core during reactor operation; they fall into the core due to gravity in response to a scram signal to terminate the nuclear chain reaction. (2) There are 6 shim rods (KO1 through KO6); they are partially withdrawn from the core during normal operation and are adjusted during operation to maintain criticality; these rods also fall into core due to gravity in response to a scram signal. (3) There is 1 automatic rod (AR); it is partially withdrawn from the core during normal operation and its drive motor is attached to a logic circuit used to maintain (or make programmed adjustments to) power; it does participate in scram (but this small additional worth is ignored in the ANL transient calculations). The 
reactivity worths of $\mathrm{CR}$ are shown in Table 2.5.2. With some exceptions, individual control rod worths increase for each of the different core configurations.

Table 2.5.2: Control Rod Worths [\$]

\begin{tabular}{|c|c|c|c|c|c|}
\hline Core: & $10+17+0$ & $10+17+10$ & $10+17+16$ & $10+17+23$ & $10+17+49$ \\
\hline Cycle: & 1 & 4 & 10 & 12 & 15 \\
\hline $\mathrm{AZ1}$ & 1.16 & 1.08 & 1.20 & 1.72 & 1.86 \\
\hline$A Z 2$ & 1.34 & 1.75 & 1.84 & 1.83 & 1.97 \\
\hline AZ3 & 1.26 & 1.64 & 1.73 & 1.86 & 2.00 \\
\hline All $A Z$ & 4.02 & 4.85 & 5.14 & 5.92 & 6.76 \\
\hline KO1 & 1.38 & 1.65 & 1.90 & 2.04 & 2.16 \\
\hline $\mathrm{KO} 2$ & 2.57 & 2.96 & 3.32 & 3.11 & 3.16 \\
\hline KO3 & 2.81 & 2.59 & 2.53 & 3.17 & 3.27 \\
\hline KO4 & 1.42 & 1.70 & 1.69 & 2.12 & 2.68 \\
\hline KO5 & 1.74 & 1.93 & 1.76 & 2.19 & 2.41 \\
\hline KO6 & 2.55 & 3.21 & 3.08 & 3.07 & 3.21 \\
\hline$A R$ & 0.35 & 0.42 & 0.57 & 0.51 & 0.54 \\
\hline $\begin{array}{l}\text { Shutdown } \\
\text { Margin } \\
(K O+A R)\end{array}$ & 2.51 & 2.24 & 7.25 & 7.25 & 9.14 \\
\hline $\begin{array}{l}\text { All Rods } \\
(K O+A R+A Z)\end{array}$ & 6.65 & 7.25 & 12.97 & 13.72 & 16.66 \\
\hline & & & & & \\
\hline
\end{tabular}

As mentioned above, there are detection, processing, and action circuits in order to automatically respond to various emergency conditions. Upon detection of a low-level variance the operator is given a warning signal. If the variance exceeds a certain level the systems will take automatic actions intended to bring the reactor to a safe, shut down condition. One of these actions is denoted "scram", which involves insertion of all CR into the core. In analysis of emergency situations, regulations require that one assumes that the highest worth safety rod is stuck and does not fall into the core. Additionally, one transient which must be analyzed involves the spontaneous withdrawal of the highest worth shim rod; the scram for this transient must consider that the withdrawing shim rod does not participate in the scram; therefore there are two scram reactivity insertions associated with each core. As a reminder, when adding or removing a CR from the calculation, one must redo the neutronics calculation rather than merely deducting the worth of the CR from the total - the individual worths are not directly additive because of the shadowing factor. 


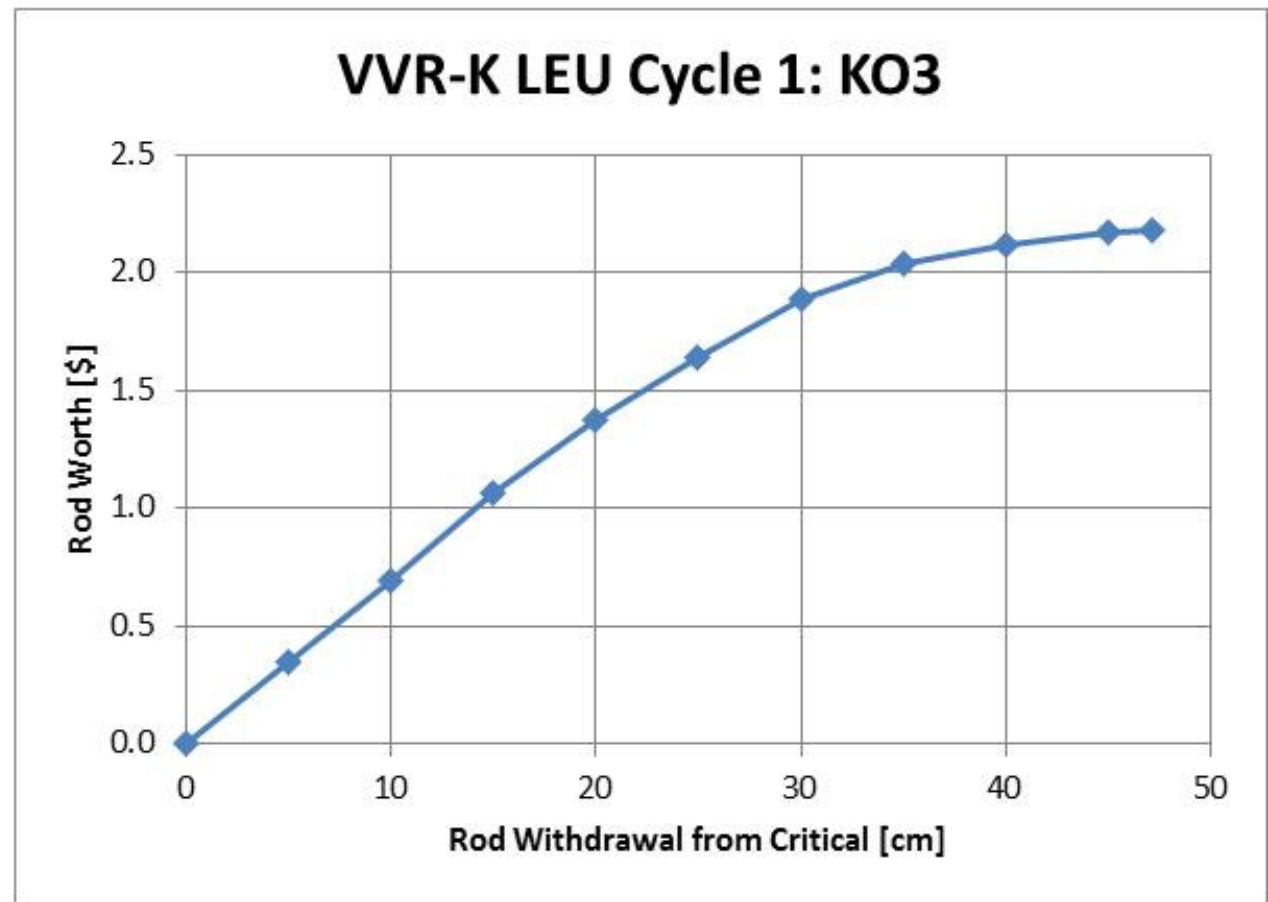

Figure 2.5.1 KO3 Rod Worth as Function of Withdrawal for Cycle 1

centimeter and decreases as the CR is withdrawn further from the core.
Table 2.5.3 shows the $\mathrm{CR}$ worth as a function of withdrawal from critical position for the highest worth shim rod for each core. (The last line of table shows the worth for the maximum possible withdrawal of the indicated rod.) As an example, Figure 2.5.1 shows the worth of shim rod $\mathrm{KO} 3$ in Cycle 1 core as a function of withdrawal position.

The initial $\mathrm{CR}$ movement has the highest worth per

Table 2.5.3: Worth $[\$]$ versus Withdrawal $[\mathrm{cm}]$ for Maximum Worth Shim Rod

\begin{tabular}{|l|c|c|c|c|c|}
\hline Core: & $\mathbf{1 0 + 1 7 + 0}$ & $\mathbf{1 0 + 1 7 + 1 0}$ & $\mathbf{1 0 + 1 7 + 1 6}$ & $\mathbf{1 0 + 1 7 + 2 3}$ & $\mathbf{1 0 + 1 7 + 4 9}$ \\
\hline Cycle: & $\mathbf{1}$ & $\mathbf{4}$ & $\mathbf{1 0}$ & $\mathbf{1 2}$ & $\mathbf{1 5}$ \\
\hline Max Shim: & $\mathbf{K O 3}$ & $\mathbf{K O 6}$ & $\mathbf{K O 2}$ & $\mathbf{K O 3}$ & KO3 \\
\hline Withdrawal [cm] & & & & & \\
\hline 0 & 0 & 0 & 0 & 0 & 0 \\
\hline 5 & 0.345 & 0.355 & 0.425 & 0.394 & 0.398 \\
\hline 10 & 0.697 & 0.746 & 0.784 & 0.755 & 0.731 \\
\hline 15 & 1.063 & 1.162 & 1.101 & 1.044 & 1.000 \\
\hline 20 & 1.371 & 1.564 & 1.348 & 1.298 & 1.188 \\
\hline 25 & 1.643 & 1.918 & 1.520 & 1.474 & 1.347 \\
\hline 30 & 1.882 & 2.195 & 1.645 & 1.602 & 1.435 \\
\hline 35 & 2.035 & 2.423 & 1.694 & 1.666 & 1.478 \\
\hline 40 & 2.118 & 2.577 & & & \\
\hline 45 & 2.166 & 2.674 & & & \\
\hline maximum $[\$ \mathrm{~cm}]$ & $2.176 @ 47.2$ & $2.697 @ 49.6$ & $1.705 @ 37.6$ & $1.702 @ 39.6$ & $1.500 @ 36.8$ \\
\hline
\end{tabular}

Table 2.5.4 shows the reactivity inserted during scram as a function of position of lower end of the CR. Two numbers are shown in style " $A / B$ "; the value in the " $A$ " position omits the highest worth safety rod but include all shim rods; the value in the " $B$ " position omits the highest worth safety rod and highest worth shim rod. All CR insertions are negative reactivity; however, the "minus sign" has been omitted in the table. An illustration of reactivity due to CR insertion is shown in Figure 2.5.2 for Cycle 1; curve 
"AZ1+AZ3+KO" in Figure 2.5.2 is " $A$ " from Table 2.5.4, and "AZ1+AZ3+KO-KO3" in Figure 2.5.2 is " $B$ " from Table 2.5.4. CR insertion of only 5 to $10 \mathrm{~cm}$ is required to insert more than $1 \$$ of reactivity, and, thus, lead to termination of the nuclear chain reaction in all transients to be analyzed later in this report. The shutdown reactivity for Cycles 10, 12, and 15 are much higher than those for Cycles 1 and 4 due to the amount of neutron reflection caused by the presence of the Be blocks.

Table 2.5.4: Scram Reactivity Inserted $[\$]$ as Function of Position (see text)

\begin{tabular}{|l|c|c|c|c|c|}
\hline Core: & $\mathbf{1 0 + 1 7 + 0}$ & $\mathbf{1 0 + 1 7 + 1 0}$ & $\mathbf{1 0 + 1 7 + 1 6}$ & $\mathbf{1 0 + 1 7 + 2 3}$ & $\mathbf{1 0 + 1 7 + 4 9}$ \\
\hline Cycle: & $\mathbf{1}$ & $\mathbf{4}$ & $\mathbf{1 0}$ & $\mathbf{1 2}$ & $\mathbf{1 5}$ \\
\hline Max Safety: & $\mathbf{A Z 2}$ & $\mathbf{A Z 2}$ & $\mathbf{A Z 2}$ & $\mathbf{A Z 3}$ & AZ3 \\
\hline Max Shim: & KO3 & KO6 & KO2 & KO3 & KO3 \\
\hline & & & & & \\
\hline Position $[\mathbf{c m}]$ & & & & & $0 / 0$ \\
\hline 0 & $0 / 0^{\text {a }}$ & $0 / 0$ & $0 / 0$ & 0 & 0 \\
\hline 5 & $1.212 / 0.955$ & $1.155 / 0.920$ & $1.972 / 1.521$ & $2.183 / 1.739$ & $2.274 / 1.819$ \\
\hline 10 & $2.041 / 1.627$ & $1.890 / 1.501$ & $3.972 / 3.026$ & $4.298 / 3.439$ & $4.693 / 3.762$ \\
\hline 15 & $2.558 / 1.826$ & $2.266 / 1.836$ & $5.723 / 4.369$ & $6.050 / 4.888$ & $6.954 / 5.613$ \\
\hline 20 & $2.858 / 2.358$ & $2.577 / 2.135$ & $7.041 / 5.374$ & $7.242 / 5.925$ & $8.731 / 7.111$ \\
\hline 25 & $3.134 / 2.615$ & $2.876 / 2.415$ & $7.873 / 6.065$ & $7.986 / 6.594$ & $9.907 / 8.137$ \\
\hline 30 & $3.448 / 2.911$ & $3.242 / 2.745$ & $8.402 / 6.517$ & $8.464 / 7.063$ & $10.629 / 8.812$ \\
\hline 35 & $3.800 / 3.241$ & $3.616 / 3.123$ & $8.757 / 6.926$ & $8.912 / 7.501$ & $11.125 / 9.340$ \\
\hline 40 & $4.101 / 3.562$ & $4.000 / 3.503$ & $9.237 / 7.371$ & $9.346 / 7.983$ & $11.647 / 9.912$ \\
\hline 45 & $4.410 / 3.877$ & $4.337 / 3.847$ & $9.613 / 7.775$ & $9.745 / 8.453$ & $12.101 / 10.466$ \\
\hline 50 & $4.656 / 4.134$ & $4.611 / 4.126$ & $10.139 / 8.124$ & $10.301 / 8.875$ & $12.737 / 10.951$ \\
\hline 55 & $4.826 / 4.342$ & $4.778 / 4.318$ & $10.261 / 8.407$ & $10.448 / 9.171$ & $12.903 / 11.306$ \\
\hline 60 & $4.934 / 4.453$ & $4.907 / 4.432$ & $10.334 / 8.568$ & $10.500 / 9.357$ & $12.963 / 11.506$ \\
\hline 65 & $4.949 / 4.505$ & $4.945 / 4.485$ & $10.334 / 8.609$ & $10.500 / 9.419$ & $12.963 / 11.589$ \\
\hline 68 & $4.949 / 4.485$ & $4.952 / 4.497$ & $10.331 / 8.622$ & $10.500 / 9.437$ & $12.967 / 11.595$ \\
\hline
\end{tabular}

a. Notation style " $A / B$ "”" " $A$ " is " $A Z-A Z_{\max }+K O$ "; " $B$ " is " $A Z-A Z_{\max }+K O-K O_{\max }$ ". 


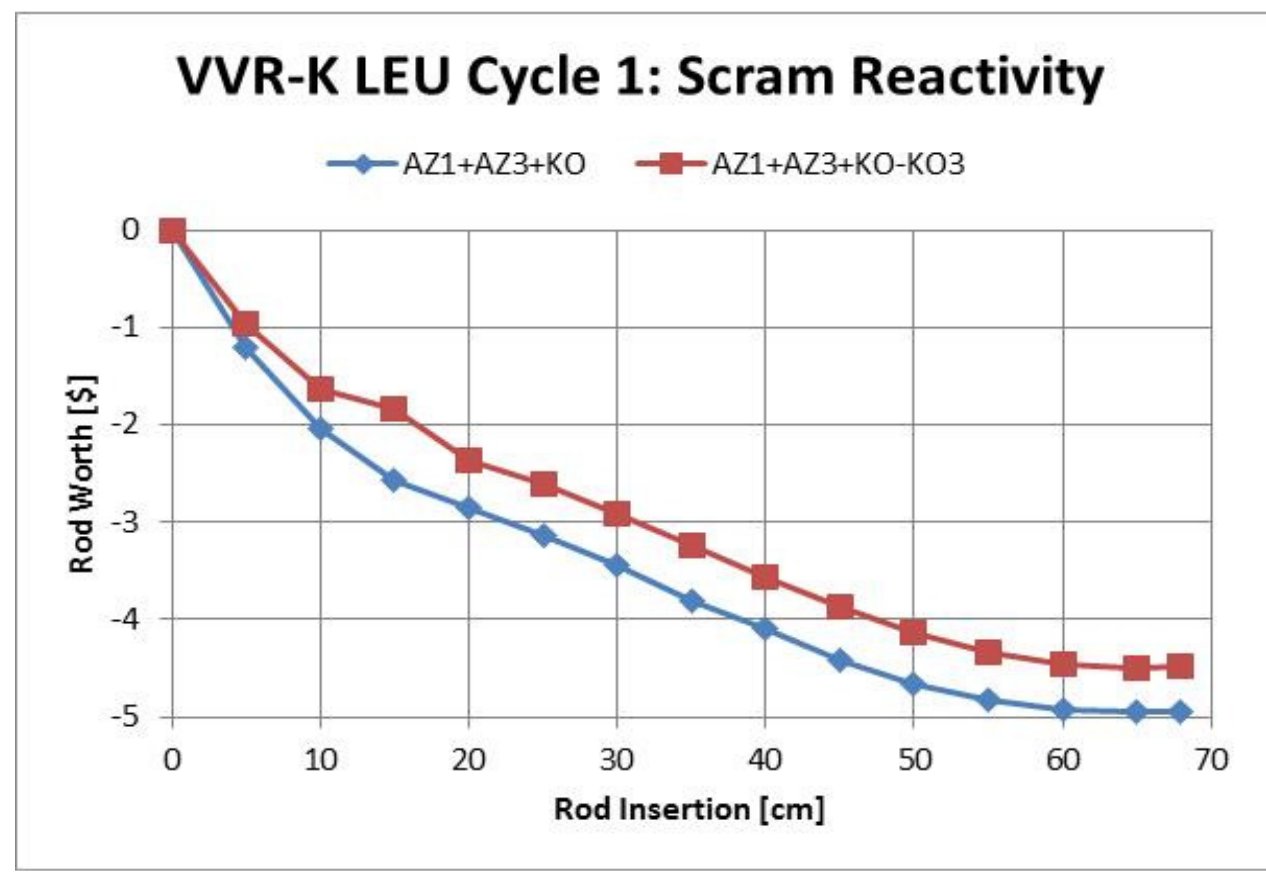

Figure 2.5.2 Scram Reactivity as Function of Rod Insertion for Cycle 1.

The reactivity feedback coefficients associated with coolant and fuel temperature changes and coolant density changes are shown in Table 2.5.5. All the reactivity coefficients are negative for the cycle in each of the different core configurations. Note that for the cores, the lateral reflector temperature (either water or $\mathrm{Be}$ ) was considered to be equal to room temperature.

Table 2.5.5: Temperature and Density Reactivity Feedback Coefficients

\begin{tabular}{|c|c|c|c|c|c|}
\hline Core: & $10+17+0$ & $10+17+10$ & $10+17+16$ & $10+17+23$ & $10+17+49$ \\
\hline Cycle: & 1 & 4 & 10 & 12 & 15 \\
\hline \multicolumn{6}{|l|}{$\begin{array}{l}\text { Coolant Temp } \\
{[\$ / K]}\end{array}$} \\
\hline $294<T<350 \mathrm{~K}$ & $-1.2212 \mathrm{E}-2$ & $-1.4257 \mathrm{E}-2$ & $-1.5585 \mathrm{E}-2$ & $-1.6154 \mathrm{E}-2$ & $-1.7711 \mathrm{E}-2$ \\
\hline $350<T<400 \mathrm{~K}$ & $-1.3180 \mathrm{E}-2$ & $-1.4844 \mathrm{E}-2$ & $-1.6147 \mathrm{E}-2$ & $-1.6624 \mathrm{E}-2$ & $-1.8081 E-2$ \\
\hline $294<T<400 \mathrm{~K}$ & $-1.2667 \mathrm{E}-2$ & $-1.4533 \mathrm{E}-2$ & $-1.5849 \mathrm{E}-2$ & $-1.6375 E-2$ & $-1.7885 \mathrm{E}-2$ \\
\hline \multicolumn{6}{|l|}{$\begin{array}{l}\text { Coolant } \\
\text { Density }[\$ / \%]\end{array}$} \\
\hline $0-5 \%$ & -0.41245 & -0.38739 & -0.35146 & -0.32806 & -0.29565 \\
\hline $5-10 \%$ & -0.44670 & -0.41992 & -0.38167 & -0.35766 & -0.32172 \\
\hline $0-10 \%$ & -0.42958 & -0.40366 & -0.36657 & -0.34286 & -0.30868 \\
\hline \multicolumn{6}{|l|}{$\begin{array}{ll}\text { Fuel } & \text { Temp } \\
{[\$ / K]} & \end{array}$} \\
\hline $294<T<400 \mathrm{~K}$ & $-2.9287 \mathrm{E}-3$ & $-3.1118 \mathrm{E}-3$ & $-3.3895 \mathrm{E}-3$ & $-3.4184 \mathrm{E}-3$ & $-3.5509 E-3$ \\
\hline $400<T<500 \mathrm{~K}$ & $-2.5861 \mathrm{E}-3$ & $-2.8002 \mathrm{E}-3$ & $-2.9498 \mathrm{E}-3$ & $-3.0876 \mathrm{E}-3$ & $-3.1825 \mathrm{E}-3$ \\
\hline $500<T<600 \mathrm{~K}$ & $-2.3591 \mathrm{E}-3$ & $-2.5954 \mathrm{E}-3$ & $-2.8281 \mathrm{E}-3$ & $-2.8349 \mathrm{E}-3$ & $-3.0194 \mathrm{E}-3$ \\
\hline $294<T<600 \mathrm{~K}$ & $-2.6280 \mathrm{E}-3$ & $-2.8415 \mathrm{E}-3$ & $-3.0627 E-3$ & $-3.1200 \mathrm{E}-3$ & $-3.2572 \mathrm{E}-3$ \\
\hline
\end{tabular}




\subsection{Core Power}

The power produced in each FA of each of the five cores is shown in Table 2.6.1 for a total core power of $6 \mathrm{MW}$. Peak FA power occurs in core position 6-5 in all of these cores; peak FA power is $0.409 \mathrm{MW}$ in Cycle 1 and decreases in later cycles.

Table 2.6.1 Power by FA in Each Core

\begin{tabular}{|c|c|c|c|c|c|}
\hline Core: & $10+17+0$ & $10+17+10$ & $10+17+16$ & $10+17+23$ & $10+17+49$ \\
\hline Cycle: & 1 & 4 & 10 & 12 & 15 \\
\hline Core Position & Power [MW] & Power [MW] & Power [MW] & Power [MW] & Power [MW] \\
\hline $7-3(A Z 1)$ & 0.18402 & 0.17536 & 0.17298 & 0.19089 & 0.20212 \\
\hline 9-4 (AZ2) & 0.20439 & 0.21496 & 0.20621 & 0.20409 & 0.21329 \\
\hline $5-8(A Z 3)$ & 0.19596 & 0.20514 & 0.19436 & 0.19684 & 0.20104 \\
\hline 4-3 (KO1) & 0.13539 & 0.12885 & 0.15455 & 0.15572 & 0.16432 \\
\hline 4-6 (KO2) & 0.16133 & 0.16206 & 0.18551 & 0.17439 & 0.17953 \\
\hline $6-3(\mathrm{KO})$ & 0.14667 & 0.13629 & 0.15834 & 0.16834 & 0.17512 \\
\hline $7-8$ (KO4) & 0.13693 & 0.13680 & 0.15527 & 0.15930 & 0.17061 \\
\hline 8-3 (KO5) & 0.13247 & 0.12797 & 0.13943 & 0.14590 & 0.15527 \\
\hline 8-6 (KO6) & 0.16314 & 0.15776 & 0.18078 & 0.17751 & 0.18487 \\
\hline $3-2(A R)$ & 0.18495 & 0.18712 & 0.18899 & 0.17825 & 0.17683 \\
\hline Sum FA-2 & 1.6452 & 1.6323 & 1.7364 & 1.7512 & 1.8230 \\
\hline Average FA-2 & 0.16452 & 0.16323 & 0.17364 & 0.17512 & 0.18230 \\
\hline $9-3$ & 0.17478 & 0.18833 & 0.18643 & 0.19178 & 0.20544 \\
\hline $8-4$ & 0.23901 & 0.24643 & 0.23532 & 0.23838 & 0.23599 \\
\hline $8-5$ & 0.27366 & 0.27744 & 0.26420 & 0.25930 & 0.25527 \\
\hline $8-7$ & 0.17352 & 0.18451 & 0.19464 & 0.20099 & 0.21179 \\
\hline $7-4$ & 0.24928 & 0.24049 & 0.23186 & 0.24366 & 0.23932 \\
\hline $7-6$ & 0.33282 & 0.32906 & 0.30263 & 0.29389 & 0.27769 \\
\hline $7-7$ & 0.23718 & 0.24441 & 0.23885 & 0.24041 & 0.23520 \\
\hline $6-4$ & 0.33420 & 0.31577 & 0.29391 & 0.29258 & 0.27583 \\
\hline $6-5$ & 0.40925 & 0.38911 & 0.34832 & 0.33465 & 0.30791 \\
\hline $6-7$ & 0.24846 & 0.25552 & 0.24648 & 0.25144 & 0.24850 \\
\hline $5-3$ & 0.18101 & 0.17594 & 0.18832 & 0.20335 & 0.21737 \\
\hline $5-4$ & 0.23769 & 0.23074 & 0.23466 & 0.23920 & 0.23329 \\
\hline $5-6$ & 0.32971 & 0.32217 & 0.30800 & 0.29434 & 0.27681 \\
\hline $5-7$ & 0.24721 & 0.25824 & 0.25478 & 0.25048 & 0.24438 \\
\hline $4-4$ & 0.23873 & 0.23889 & 0.24979 & 0.24348 & 0.23732 \\
\hline $4-5$ & 0.25886 & 0.26307 & 0.26728 & 0.25481 & 0.24748 \\
\hline $4-7$ & 0.18941 & 0.20759 & 0.21812 & 0.21601 & 0.22741 \\
\hline Sum FA-1 & 4.3548 & 4.36771 & 4.2636 & 4.2488 & 4.1770 \\
\hline Average FA-1 & 0.25616 & 0.25692 & 0.20580 & 0.24993 & 0.24571 \\
\hline Sum core & 6.0000 & 6.0000 & 6.0000 & 6.0000 & 6.0000 \\
\hline
\end{tabular}


Within each FA the power density varies from FE to $\mathrm{FE}$, as well as variations in axial and azimuthal directions. An example is shown in Figure 2.6.1 for the peak power FA at Cycle 1. Tube 1 is the outer tube and tube number increases moving inward. In general, power density decreases moving inward from Tube 1 due to self shielding. The peak power density occurs 23 to $25 \mathrm{~cm}$ above bottom end of fuel meat for each tube, corresponding to 5 to $7 \mathrm{~cm}$ below core mid-plane; this is determined by the position of the control rods at the critical position for each of the cores. It is important to note that at the critical state the automatic rod (AR) is inserted to the core centerline and the KO rods are all inserted to the same height. Power density is peaked toward bottom of core due to CR being inserted from the core top.

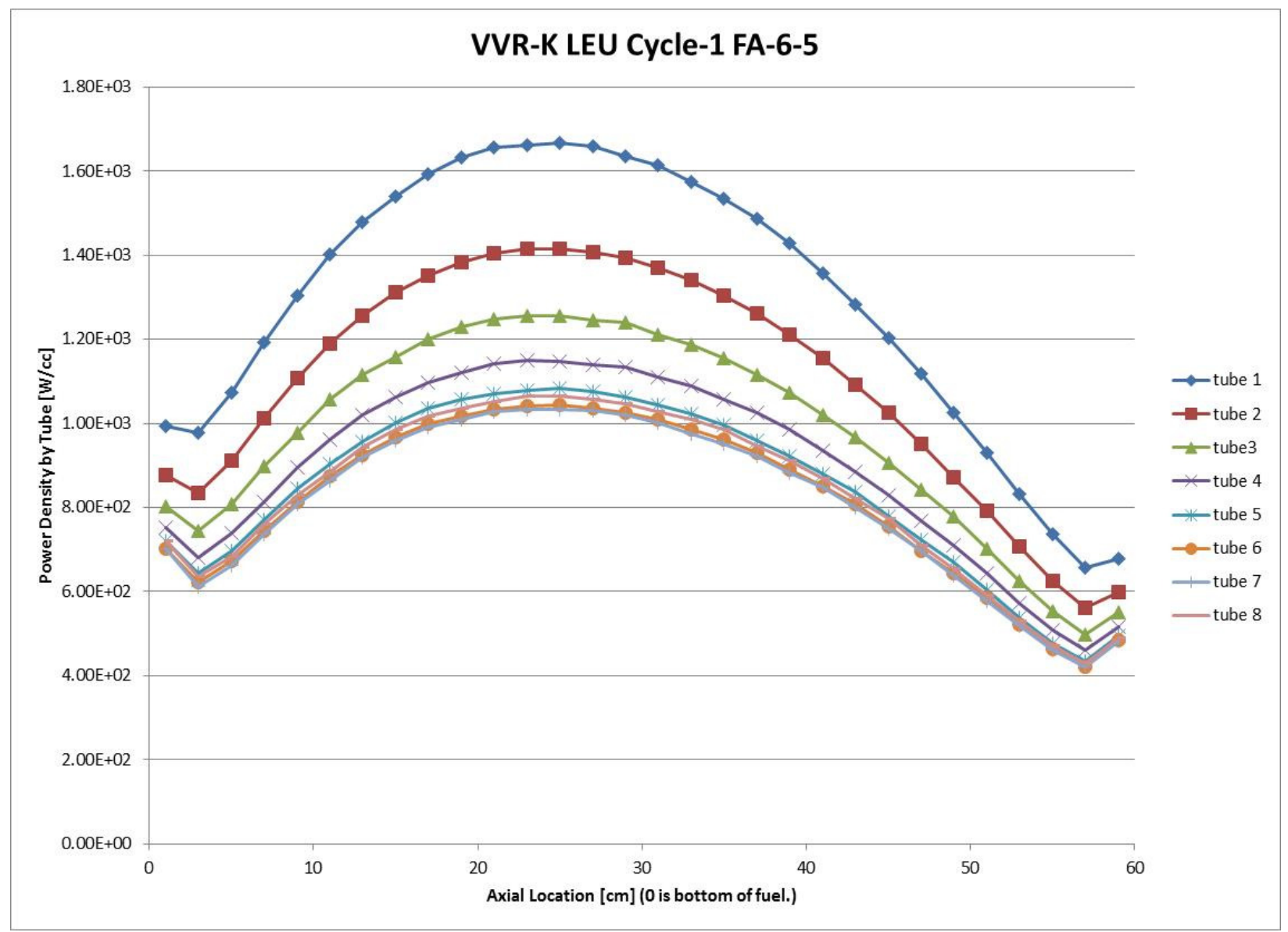

Figure 2.6.1 Axial Variation of Power Density by Tube for Peak Power FA in Cycle 1

The peak power density by tube and by axial location is shown in Figure 2.6 .2 for Cycles 4, 10, 12, and 15. The general trends are the same as shown in Figure 2.6.1 for Cycle 1. The "ragged" shape of the power density (seen most prominently in cycles 10,12, and 15) is due to the fact that the "burnup" analysis is performed using five axial zones of $12 \mathrm{~cm}$ each. 


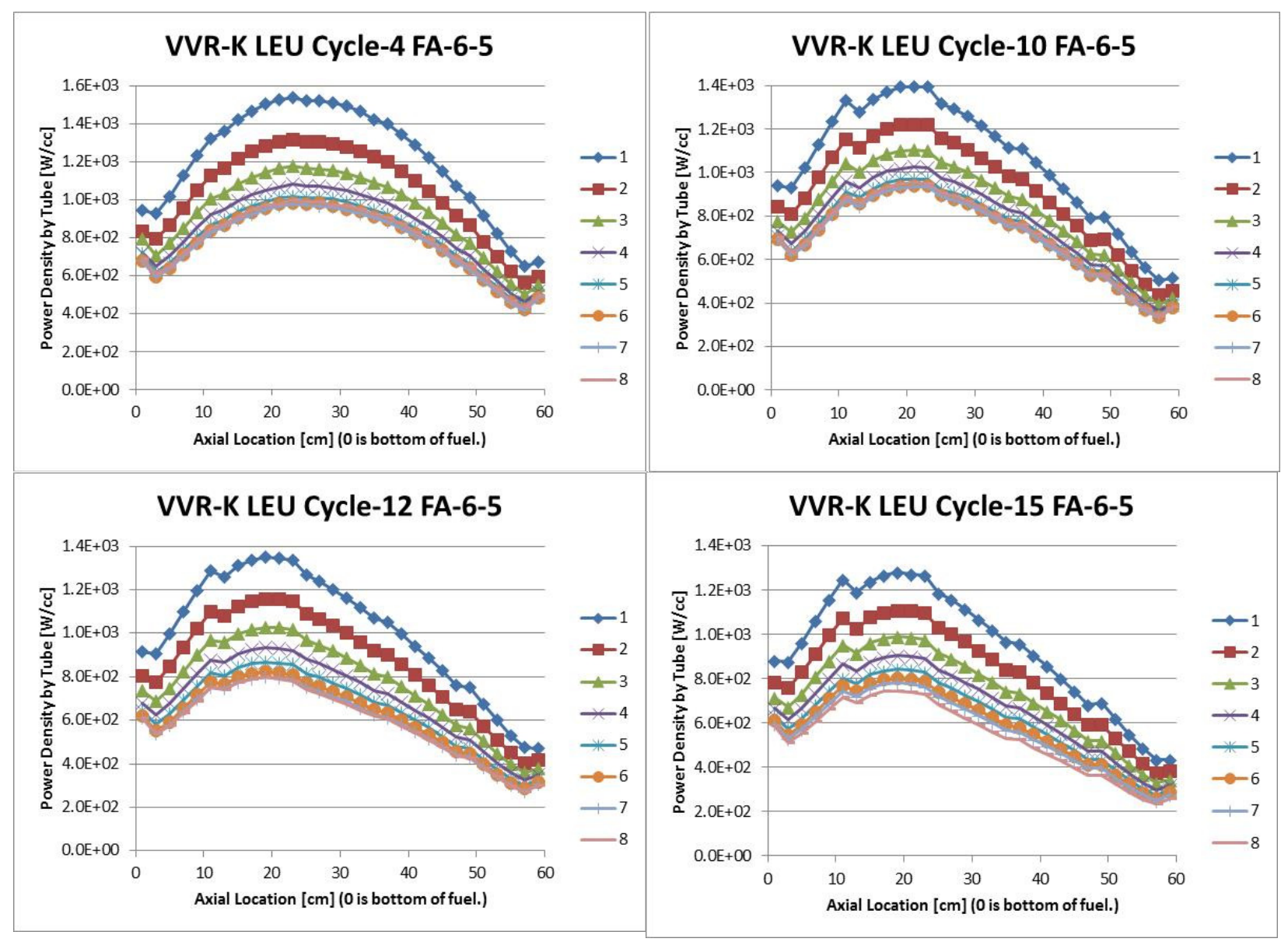

Figure 2.6.2 Peak Power Density by Tube and Axial Location for Cycles 4, 10, 12, and 15.

Peak and average power densities are shown for each core in Table 2.6.2. The maximum peak power density is usually in the peak power FA, which is at core location 6-5; for Cycle 15 the peak power density is in core location 7-7, although location 6-5 has peak FA power; the difference in the peak power density in those two FAs is only about 3\%. The peak power density of $1667 \mathrm{~W} / \mathrm{cc}$ occurs in Cycle 1 and decreases in later cycles, to $1279 \mathrm{~W} / \mathrm{cc}$ (a 24\% decrease) by Cycle 15. The average power density in FA-1 is higher than the average in FA-2. In general, the average power density in FA-1 is decreasing as irradiation proceeds, while the average in FA-2 is increasing. Since all cores produce $6 \mathrm{MW}$ and have the same fuel volume the average power density for all cores stays constant at $535 \mathrm{~W} / \mathrm{cc}$.

Table 2.6.2 Power Density [W/cc] Summary for the BOC of Each Analyzed Core

\begin{tabular}{|l|c|c|c|c|c|}
\hline Core: & $\mathbf{1 0 + 1 7 + 0}$ & $\mathbf{1 0 + 1 7 + 1 0}$ & $\mathbf{1 0 + 1 7 + 1 6}$ & $\mathbf{1 0 + 1 7 + 2 3}$ & $\mathbf{1 0 + 1 7 + 4 9}$ \\
\hline Cycle: & $\mathbf{1}$ & $\mathbf{4}$ & $\mathbf{1 0}$ & $\mathbf{1 2}$ & $\mathbf{1 5}$ \\
\hline Peak & 1667 & 1535 & 1394 & 1351 & 1279 \\
\hline Avg in Peak FA & 912 & 867 & 777 & 746 & 686 \\
\hline Avg in FA-1 & 571 & 573 & 559 & 557 & 548 \\
\hline Avg in FA-2 & 458 & 455 & 484 & 488 & 508 \\
\hline Avg in All FA & 535 & 535 & 535 & 535 & 535 \\
\hline
\end{tabular}




\section{Steady-State Thermal-Hydraulics Analysis}

\subsection{Model Description}

ANL has performed steady-state thermal-hydraulics analysis for the VVR-K cores using two computer codes: RELAP5 [7] and PLTEMP [8]. The primary ANL results are those from RELAP5, in order to be a method different from INP, which will do their analysis using PLTEMP. ANL has also performed the analysis using PLTEMP, in order to illustrate the types of code-to-code differences which can occur even when using the same input assumptions. Even though ANL and INP are both performing calculations using PLTEMP there may be some differences since ANL is using the $60-\mathrm{cm}$ design value for fuel meat length and INP is using 61-cm value for the as-delivered fuel.

The model extent is the same in both RELAP5 and PLTEMP. Each code can model a nested-tube FA as a set of material layers, alternating among water and clad-fuel-clad. The water gaps are described by flow area and hydraulic diameter (see Table 3.1.1). The FE solids are modeled as plates described by thickness of the three material layers and a perimeter (or "width" in the context of PLTEMP). The axial extent of the model covers the fuel height; all regions have the same axial mesh divisions. The PetukovPopov model for fuel to coolant heat transfer was chosen in both codes.

Coolant flow is from top to bottom. Coolant flow rate is specified for the FA, which is $18 \mathrm{~m}^{3} / \mathrm{h}$ for FA-1. The apportionment of flow among the gaps is known from measurements. In RELAP5 the entrance loss coefficient for each gap was adjusted to obtain the measured flow distribution [9]. In PLTEMP the measured flow rate distribution is directly specified. Although accomplished in different ways, the ANL analyses using RELAP5 and PLTEMP have the same flow rate distribution. The inlet coolant temperature is chosen as $45^{\circ} \mathrm{C}(318.15 \mathrm{~K})$, which is the maximum allowed during operation. The inlet pressure of $0.135 \mathrm{MPa}$ is specified at the top of the fuel element.

Table 3.1.1 FA Geometry 8-tube

\begin{tabular}{|l|l|l|l|l|l|l|}
\hline $\begin{array}{l}\text { Channel or } \\
\text { Tube }(1 \text { is } \\
\text { outer })\end{array}$ & $\begin{array}{l}\text { Flow Area } \\
{[\mathrm{m} 2]}\end{array}$ & $\begin{array}{l}\text { Perim-wet } \\
{[\mathrm{m}]}\end{array}$ & $\begin{array}{l}\text { Perim-heat } \\
{[\mathrm{m}]}\end{array}$ & $\begin{array}{l}\text { Hyd Diam } \\
{[\mathrm{m}]}\end{array}$ & $\begin{array}{l}\text { Velocity } \\
{[\mathrm{m} / \mathrm{s}]}\end{array}$ & $\begin{array}{l}\text { Fuel Tube } \\
\text { Width }[\mathrm{m}]\end{array}$ \\
\hline 1 & $4.73523 \mathrm{E}-04$ & 0.469697 & 0.225219 & $4.033 \mathrm{E}-03$ & 2.26 & 0.220193 \\
\hline 2 & $4.17080 \mathrm{E}-04$ & 0.432542 & 0.415702 & $3.857 \mathrm{E}-03$ & 2.44 & 0.195509 \\
\hline 3 & $3.66887 \mathrm{E}-04$ & 0.383175 & 0.366335 & $3.830 \mathrm{E}-03$ & 2.26 & 0.170826 \\
\hline 4 & $3.16695 \mathrm{E}-04$ & 0.333808 & 0.316968 & $3.795 \mathrm{E}-03$ & 2.20 & 0.146162 \\
\hline 5 & $2.66502 \mathrm{E}-04$ & 0.284441 & 0.267601 & $3.748 \mathrm{E}-03$ & 2.28 & 0.121459 \\
\hline 6 & $2.16309 \mathrm{E}-04$ & 0.235074 & 0.218234 & $3.681 \mathrm{E}-03$ & 2.07 & 0.096775 \\
\hline 7 & $1.66117 \mathrm{E}-04$ & 0.185707 & 0.168867 & $3.578 \mathrm{E}-03$ & 2.02 & 0.072092 \\
\hline 8 & $1.36286 \mathrm{E}-04$ & 0.125436 & 0.117016 & $4.346 \mathrm{E}-03$ & 2.44 & 0.044925 \\
\hline 9 & $0.65856 \mathrm{E}-04$ & 0.067544 & 0.039898 & $3.900 \mathrm{E}-03$ & 2.14 & (no fuel) \\
\hline
\end{tabular}

The values shown above for Channel\#1 are based on the FA being adjacent to a displacer, which is the case for peak power FA at core location 6-5 which is type FA-1, and include the full water gap. If the FA being modeled is adjacent to other FA rather than displacer(s) then the outer channel includes only half the water gap, with parameters as shown below.

\begin{tabular}{|l|l|l|l|l|l|l|}
\hline 1 & $2.40389 \mathrm{E}-04$ & 0.233099 & 0.233099 & $4.129 \mathrm{E}-03$ & 2.26 & 0.220193 \\
\hline
\end{tabular}


There are several criteria to be satisfied. The maximum clad surface temperature must be lower than $98^{\circ} \mathrm{C}$ and the minimum value for the Onset of Nucleate Boiling Ratio (ONBR) using the BerglesRohsenow correlation must be above 1.3. These criteria are to be met without using hot-channel factors. The satisfaction of these criteria can be assessed for each core by performing calculations for only the FA having peak power density. As noted in Section 2.6 this FA is in core position 6-5 for most cores but position 7-7 for Cycle 15. The power density as a function of axial position for each tube is shown in Figures 2.6.1 through 2.6.2.

\subsection{Results}

The coolant temperatures calculated using RELAP5 for Cycle 1 are shown in Figure 3.2.1. The hottest coolant is in Gap 2, which is between Tube 1 (outermost) and Tube 2; the temperature is $342 \mathrm{~K}$ at the exit, which is well below boiling. Coolant temperatures get cooler as one moves from Gap 2 toward the interior. For the hottest FA, Gap 1, which is outside of the FA, is cooler than Gaps 2 through 8; this gap is larger than the interior gaps and there is heat from only one fuel plate surface. Figure 3.2.2 shows that coolant temperatures calculated using PLTEMP for Gaps 1 through 6 are in excellent agreement (less than $1 \mathrm{~K}$ difference) with those calculated using RELAP5.

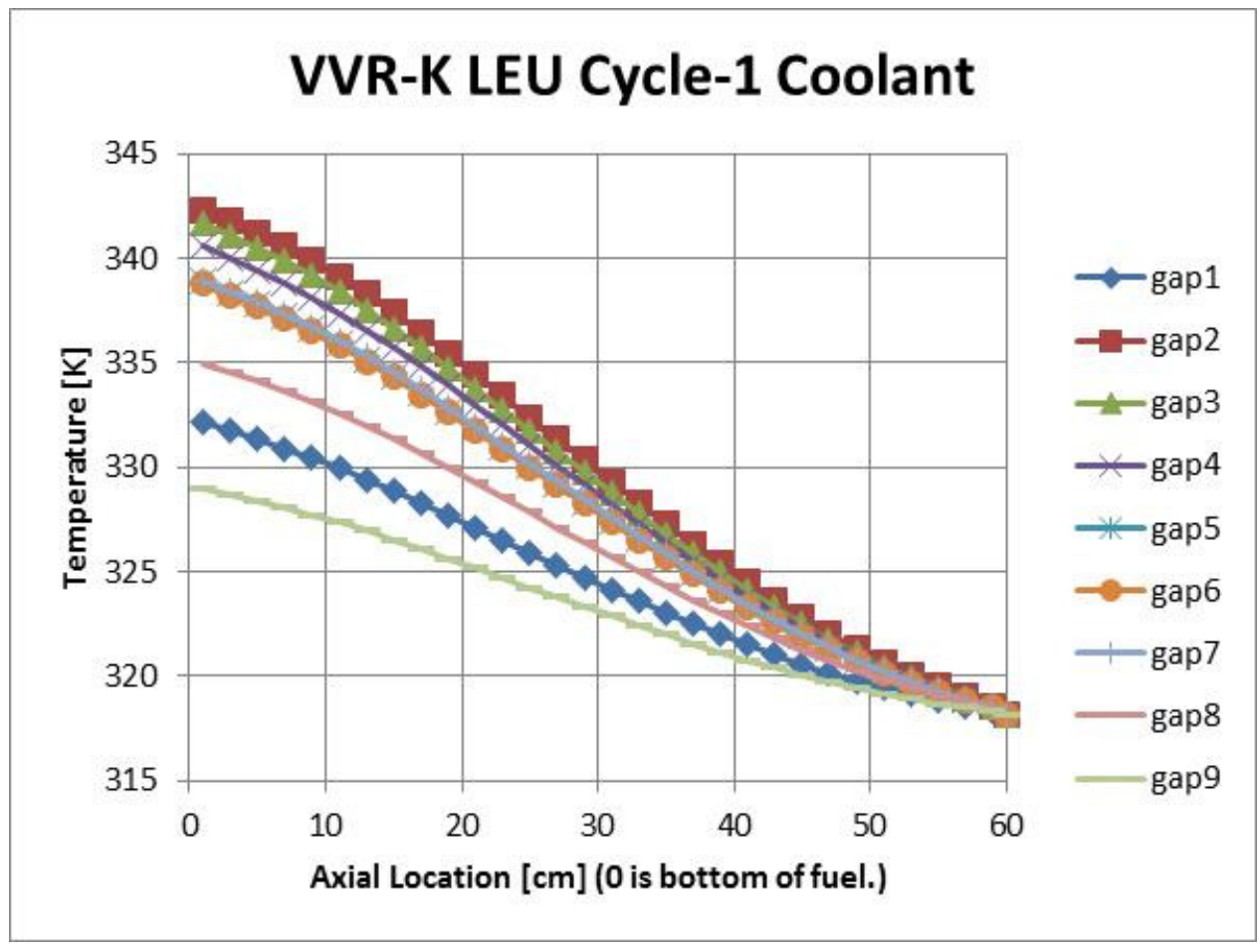

Figure 3.2.1 Coolant Temperature Calculated using RELAP5 for Cycle 1 


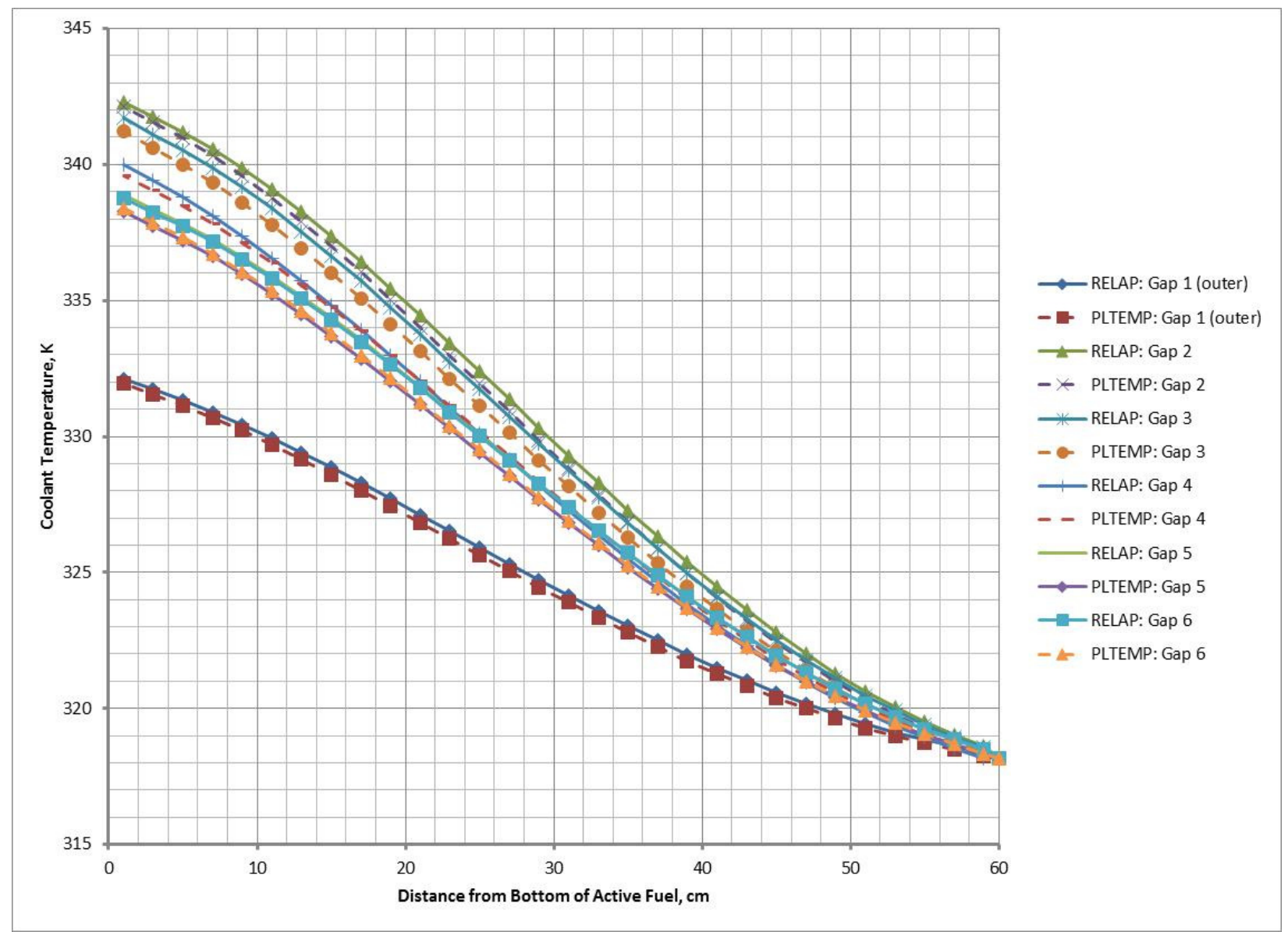

Figure 3.2.2 Comparison of Coolant Temperatures Calculated for Gaps 1-6 using RELAP5 and PLTEMP for Cycle 1

The temperatures calculated using RELAP5 for the outer and inner surface of each tube in FA having peak power are shown in Figures 3.2.3 and 3.2.4, respectively. The hottest temperature of $361 \mathrm{~K}$ occurs on the inner surface of Tube 1 a few centimeters below location of peak power density; this peak temperature is well below the damage criteria. As a reminder, Tube 1 has the peak power density.

As illustrated in Figures 3.2.5 and 3.2.6 there is almost no difference in temperature between the outer (o) and inner (i) surface of each tube as calculated using RELAP5. 


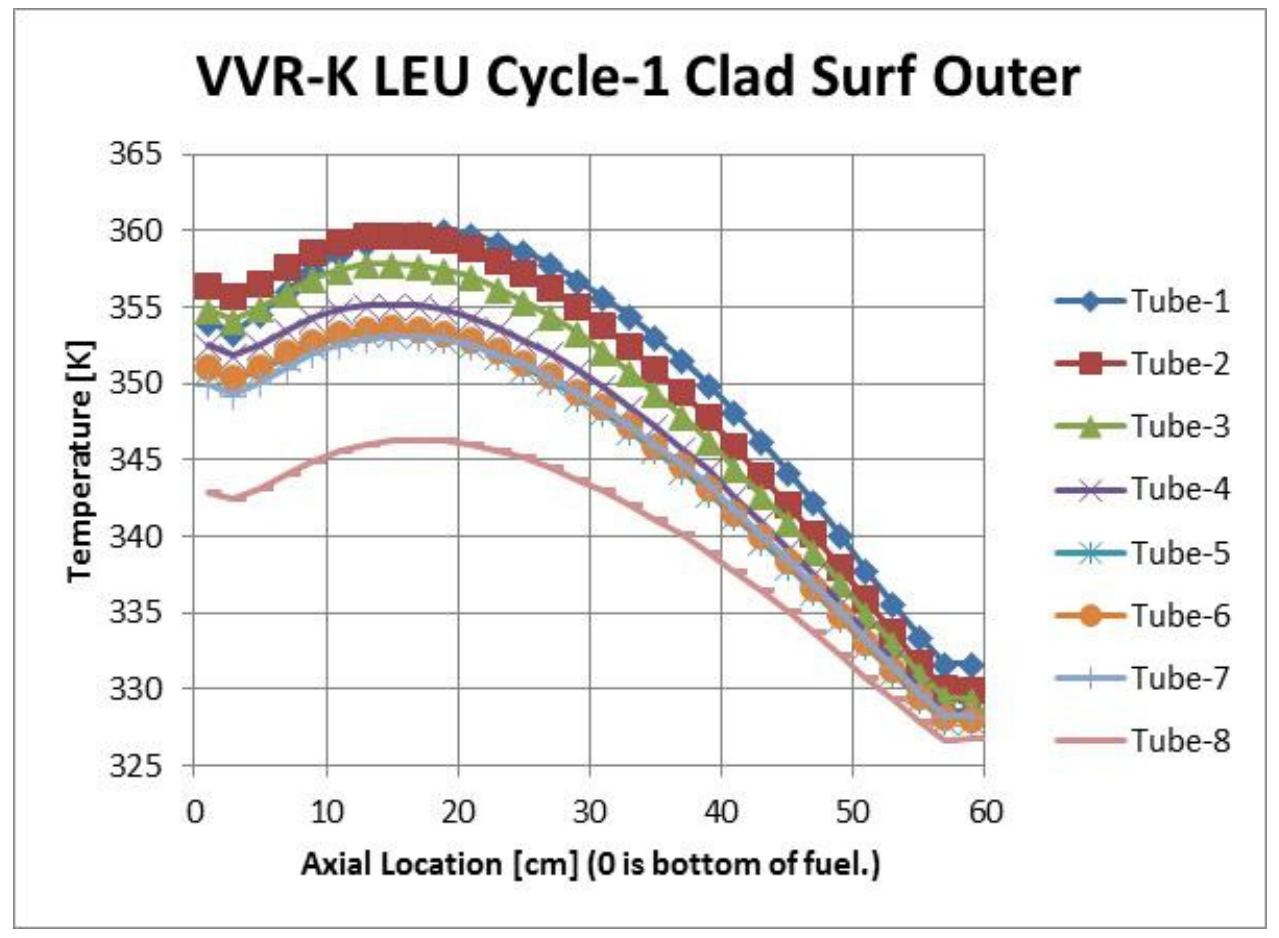

Figure 3.2.3 Outer Clad Surface Temperature Calculated using RELAP5 for Cycle 1

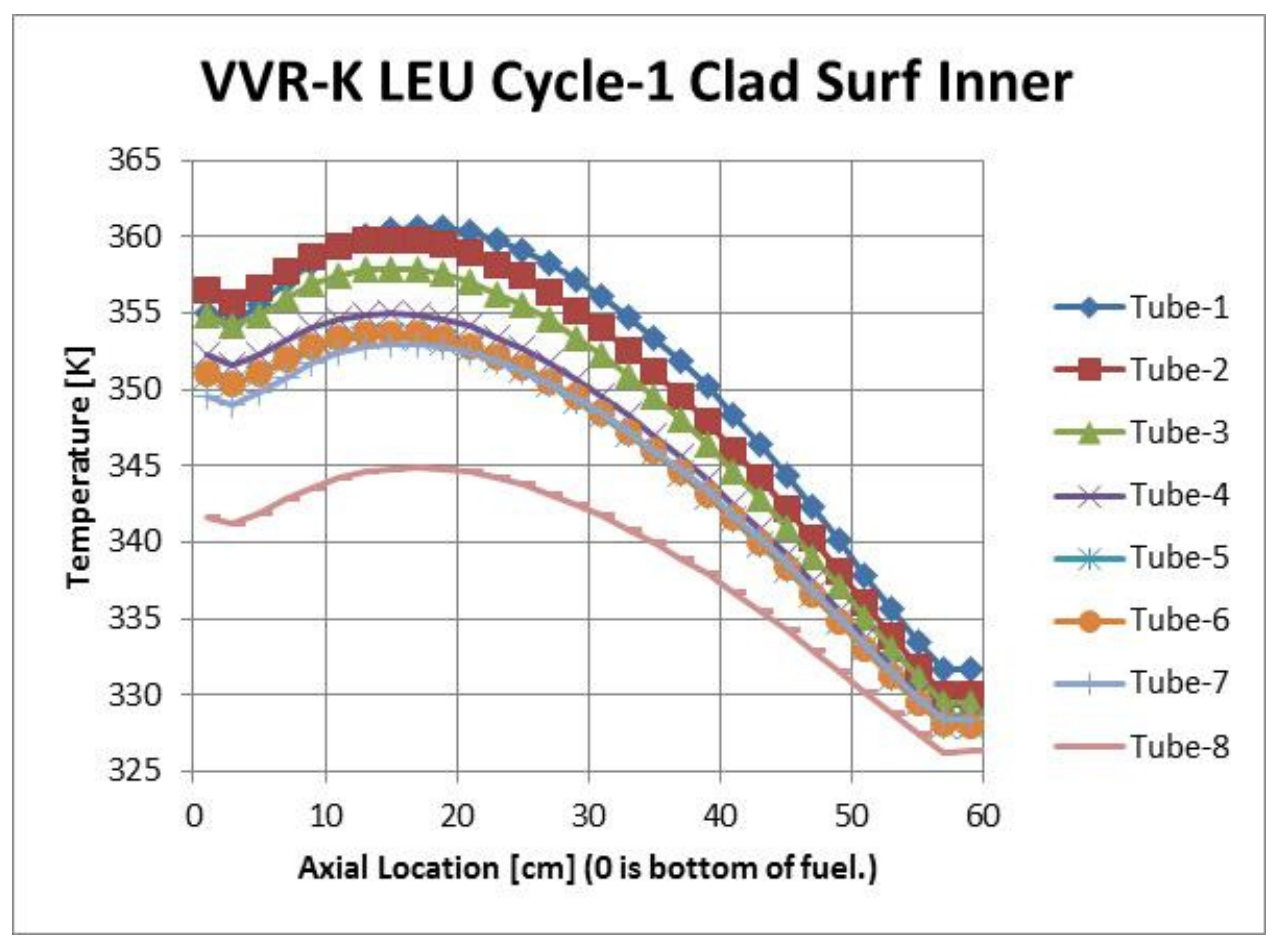

Figure 3.2.4 Inner Clad Surface Temperature Calculated using RELAP5 for Cycle 1 


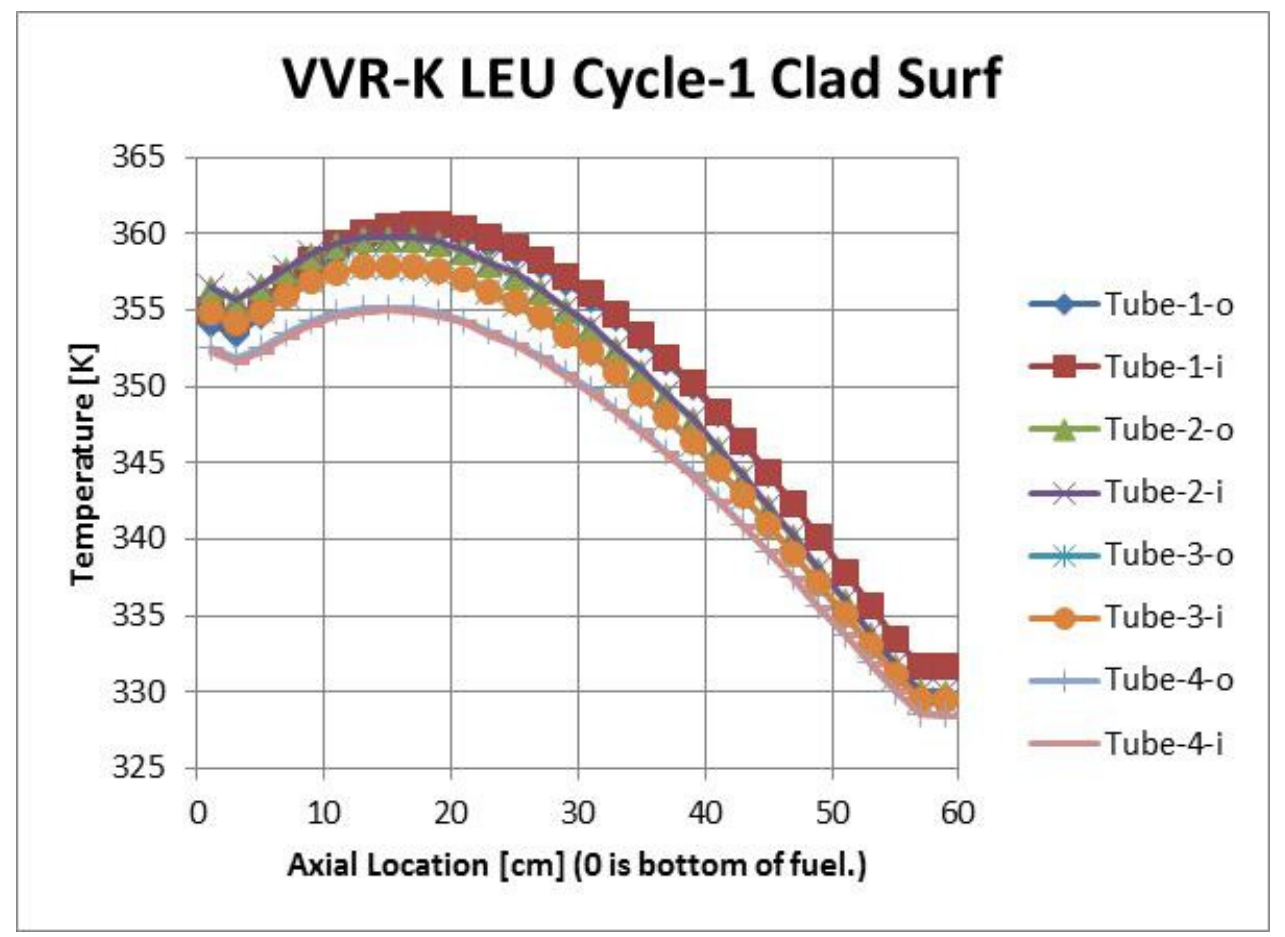

Figure 3.2.5 Comparison of Clad Surface Temperature for Tubes 1-4 Calculated using RELAP5 for Cycle 1

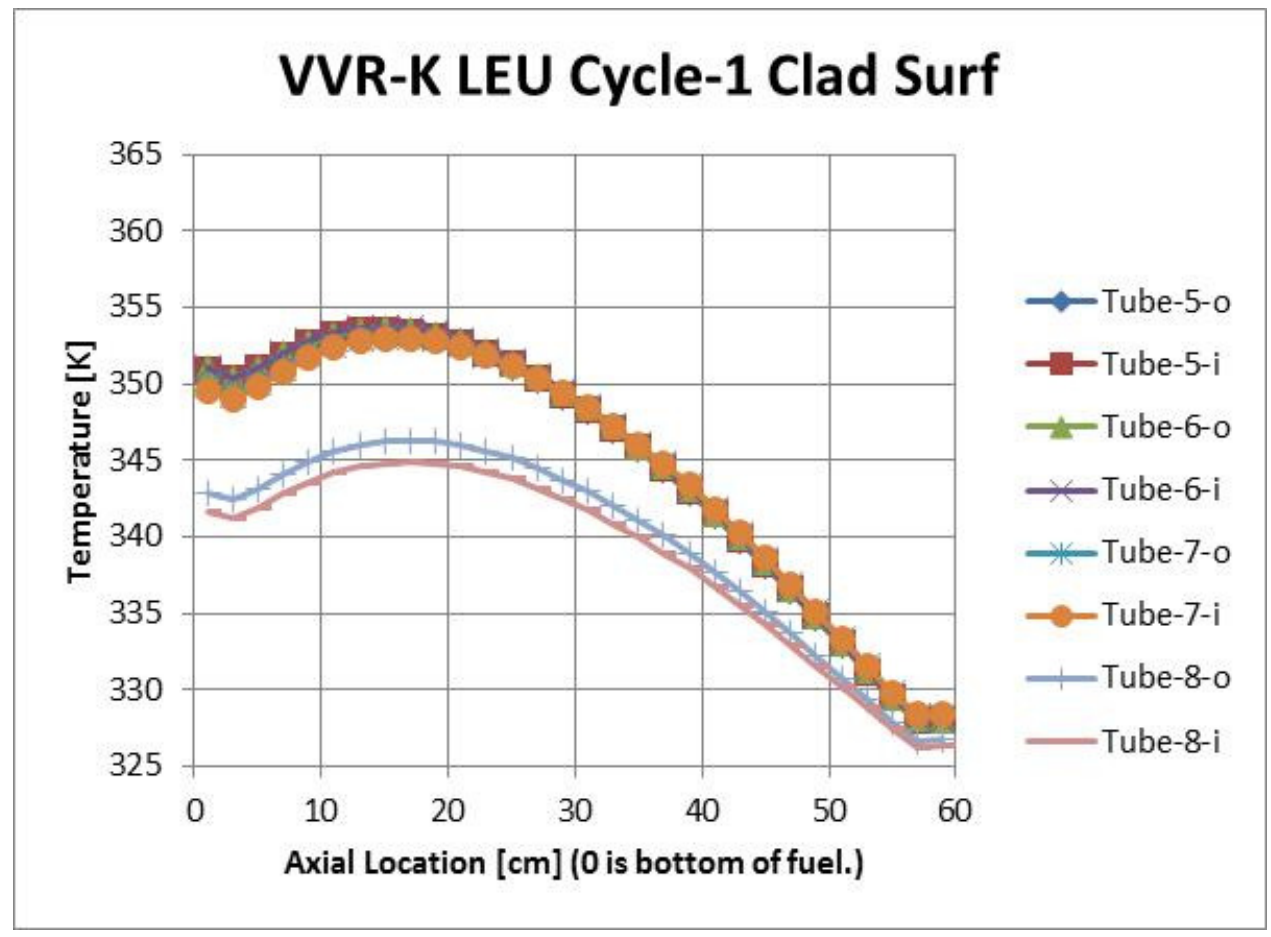

Figure 3.2.6 Comparison of Clad Surface Temperature for Tubes 5-8 Calculated using RELAP5 for Cycle 1 
Figure 3.2.7 illustrates that there is good agreement between surface temperatures calculated using PLTEMP with those calculated using RELAP5.

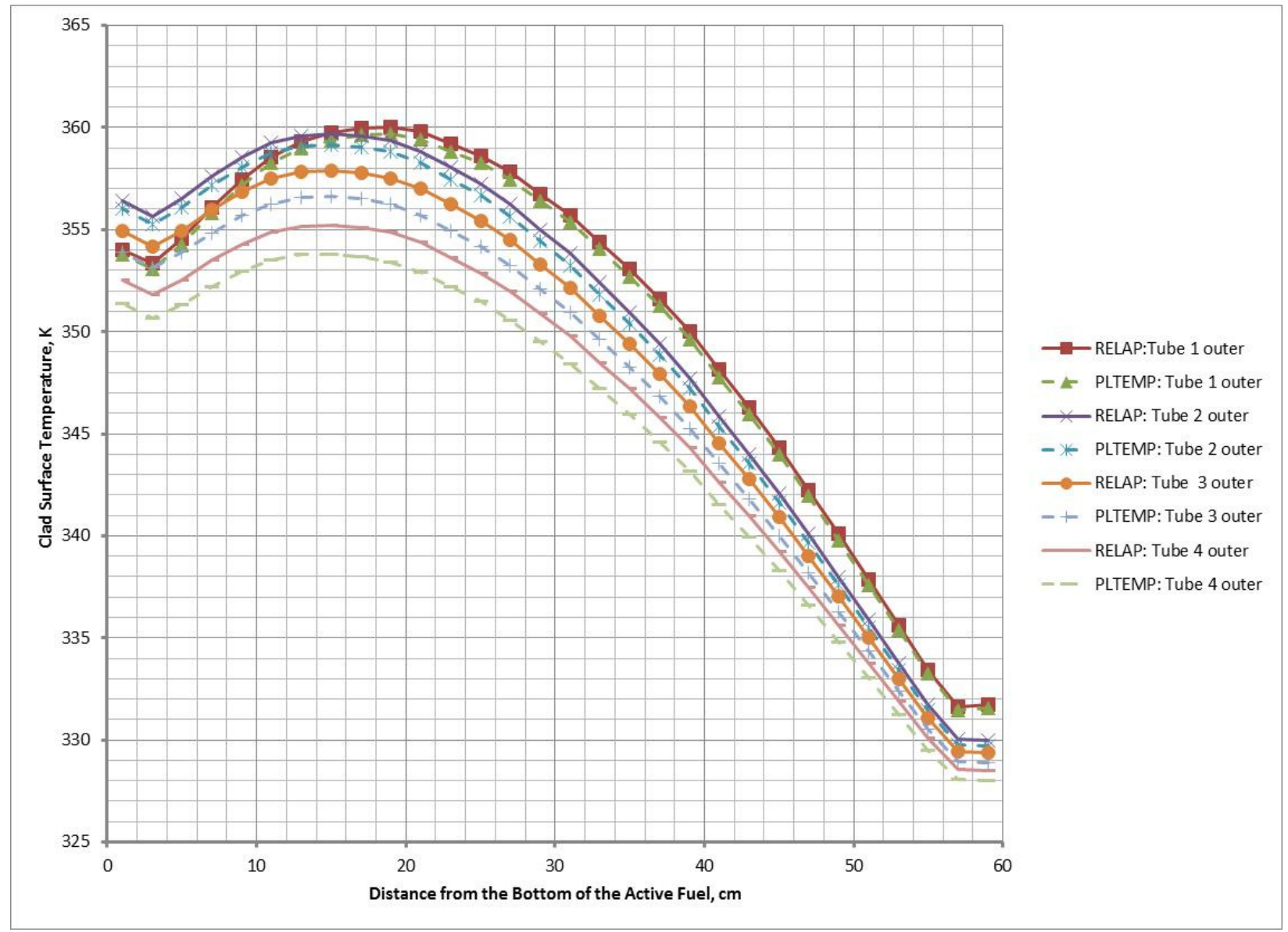

Figure 3.2.7 Comparison of PLTEMP and RELAP5 results for Clad Surface Temperature for Tubes 1-4 in Cycle 1. 
Calculations were also performed for Cycles 4, 10, 12, and 15. The power densities are the only input values which change from cycle to cycle. (In actuality, the FA coolant flow rate increases as Be blocks are added to the core. Table 3.2.1 shows this change as estimated by INP. Addition of blocks increases FA-1 flow by only $1 \%$ at Cycle 12 and by $3 \%$ at Cycle 15 . This small change was (conservatively) ignored in the ANL calculations. All cases are based on $18 \mathrm{~m}^{3} / \mathrm{h}$.) Calculated temperatures are shown in Figures 3.2.8 through 3.2.11. In general, the trends follow those seen for Cycle 1. As summarized in Table 3.2.2, the peak temperatures decrease for higher cycle numbers since the peak power per FA decreases. Peak clad temperature is less than $98^{\circ} \mathrm{C}(371 \mathrm{~K})$ design limit for all cycles analyzed. The minimum ONBR calculated for all cycles is above the 1.3 design limit.

Table 3.2.1 Effect of Be Blocks on FA Coolant Flow Rate

\begin{tabular}{|c|c|c|c|}
\hline Amount of Be (Cycle) & $\begin{array}{c}\text { Mass Flux in the core, } \\
\mathbf{k g} / \mathbf{s ~ m}^{\mathbf{2}} \text { ) }\end{array}$ & Flow Rate in FA-1, $\mathbf{~ m}^{\mathbf{3}} \mathbf{h}$ & Dp, [m of H2O column] \\
\hline 0 (Cycle 1) & 2417 & 18.00 & 1.93 \\
\hline 10 (Cycle 4) & 2435 & 18.05 & 1.938 \\
\hline 16 (Cycle 10) & 2440 & 18.09 & 1.946 \\
\hline 23 (Cycle 12) & 2450 & 18.16 & 1.96 \\
\hline 49 (Cycle 15) & 2507 & 18.60 & 2.05 \\
\hline
\end{tabular}

Table 3.2.2 Maximum Temperatures and Minimum ONBR Calculated using RELAP5 for Cycles 1, 4, 10, 12 , and 15

\begin{tabular}{|l|c|c|c|c|c|}
\hline Core: & $\mathbf{1 0 + 1 7 + 0}$ & $\mathbf{1 0 + 1 7 + 1 0}$ & $\mathbf{1 0 + 1 7 + 1 6}$ & $\mathbf{1 0 + 1 7 + 2 3}$ & $\mathbf{1 0 + 1 7 + 4 9}$ \\
\hline Cycle: & $\mathbf{1}$ & $\mathbf{4}$ & $\mathbf{1 0}$ & $\mathbf{1 2}$ & $\mathbf{1 5}$ \\
\hline Location: & $\mathbf{6 - 5}$ & $\mathbf{6 - 5}$ & $\mathbf{6 - 5}$ & $\mathbf{6 - 5}$ & $\mathbf{7 - 7}$ \\
\hline & & & & & 337 \\
\hline $\begin{array}{l}\text { Maximum Coolant } \\
\text { Temperature [K] }\end{array}$ & 342 & 341 & 338 & 354 & 352 \\
\hline $\begin{array}{l}\text { Maximum Clad Surface } \\
\text { Temperature [K] }\end{array}$ & 361 & 358 & 355 & 1.88 & 1.98 \\
\hline Minimum ONBR [-] & 1.62 & 1.73 & 1.83 & & \\
\hline
\end{tabular}




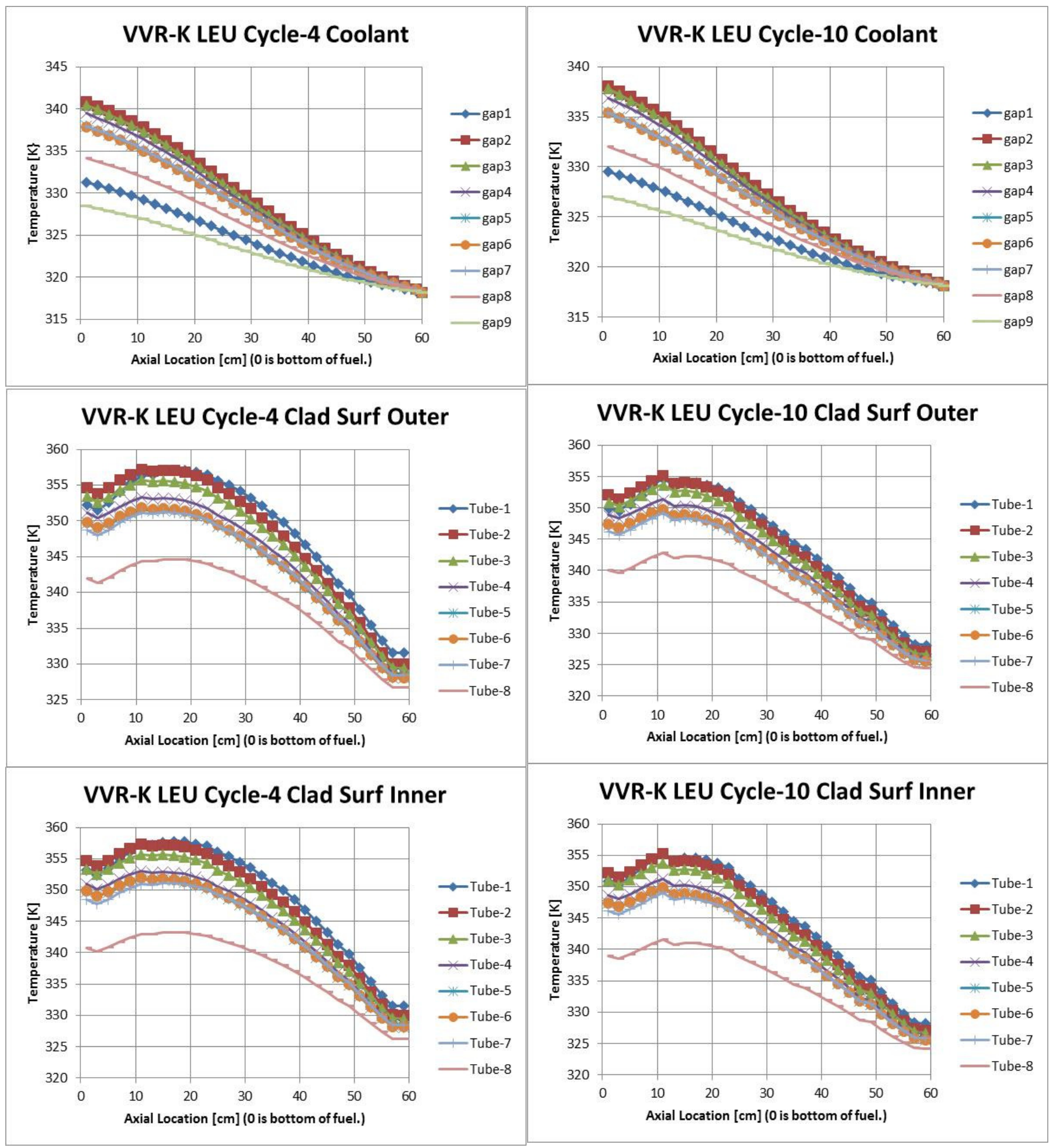

Figure 3.2.8 Coolant and Clad Surface Temperatures Calculated Figure 3.2.9 Coolant and Clad Surface Temperatures Calculated using RELAP5 for Cycle-4. using RELAP5 for Cycle-10. 


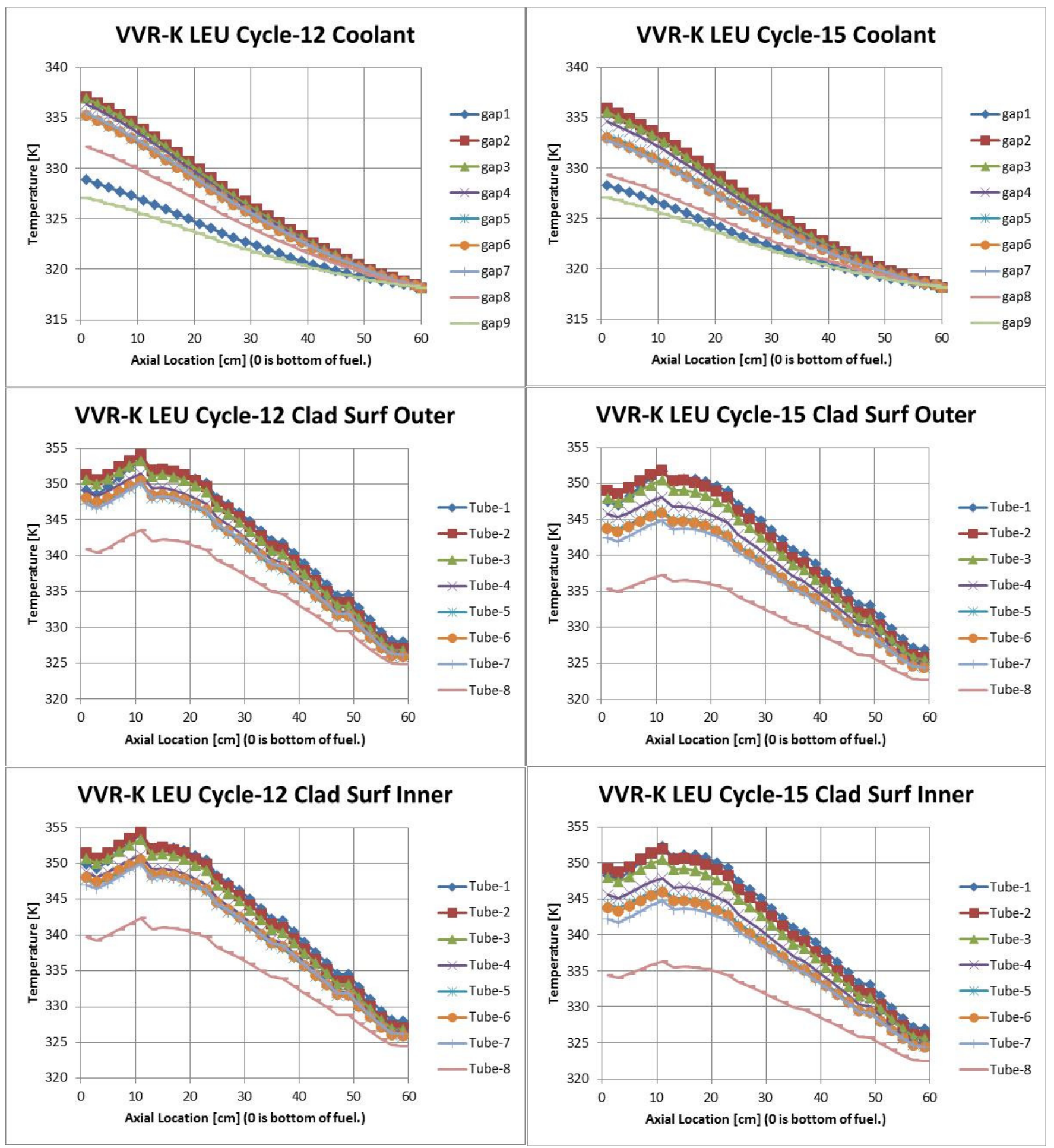

Figure 3.2.10 Coolant and Clad Surface Temperatures Calculated Figure 3.2.11 Coolant and Clad Surface Temperatures Calculated using RELAP5 for Cycle-12.

using RELAP5 for Cycle-15. 


\section{Transient Analysis}

INP provided ([10] with details in [3]) to ANL a list of nine initiating events which are potentially capable of leading to an emergency situation:

1. Personnel's mistakes in course of the work-load building-up

2. Inadvertent withdrawal of the control and protection system's most effective shim element

3. Failure of the primary-circuit main circulation pumps

4. Failure of the secondary-circuit pumps

5. Rupture of primary-circuit piping

6. Full blockage of inter-tube gaps for coolant passage in the hottest FA

7. Loss of electric power supply

8. Potential mechanical damage of FA as a result of its incidence to the core in course of its loading or changing position in the core

9. Impact of experiments and experimental devices

ANL agreed to perform detailed transient analysis for four of these, specifically numbers 2, 3, 7, and 9. ANL will also provide a scoping analysis for number 5 . For event number 6 it is assumed that the blockage of the inner-tube gaps of the hottest FA will lead to melting of the FA and therefore no "transient" analysis is required. For the other events (number 1, 4, and 8) INP informed ANL [3] that those events "do not lead to occurrence of emergency situation and as such they do not need any analysis." It is important to note here that ANL is performing these analyses at the request of INP and if INP states that no analysis is required and ANL does not have any other information to dispute that decision then no analysis is reported by ANL in this report.

ANL has performed the analysis of VVR-K transients using two computer codes: RELAP5 and PARET [11]. The primary ANL results are those from RELAP5, in order to be a method different from INP, which will do their analysis using PARET. ANL has also performed all of its analyses using PARET in order to illustrate the types of code-to-code differences which can occur even when using the same input assumptions.

The model extent is the same in both RELAP5 and PARET. Rather than the multi-channel nested-tube approach used for the steady-state calculation in Section 3, the transient model consists of two channels: hot and average. The hot channel isolates the portion of the core having the peak power density; this is treated as a half thickness of fuel meat separated by a full thickness cladding from a half thickness of water gap. The other channel also has layers of fuel, cladding, and water and represents the entire core on an average basis. In our experience this two-channel approach is sufficient for transient reactor analysis. The average channel gives appropriate reactivity feedbacks when temperatures and densities change, while the hot channel provides knowledge of the peak temperatures.

Within each channel, the water gap is described by flow area and hydraulic diameter and the FE solids are described by thickness of the material layers and a perimeter. The axial extent of the model covers the fuel height; all regions have the same axial mesh divisions. 


\subsection{Common Conditions}

The maximum normal operating power for the reactor is $6 \mathrm{MW}$. The core is assumed to have been operating at full power for full 20 day cycle. Forced convection cooling of the core is provided by two pumps operating in parallel; collectively these pumps provide $700 \mathrm{~m}^{3} / \mathrm{h}$ coolant flow during normal operation. Only a portion of this coolant flow goes through the fuel assemblies. For the initial working LEU core the flow rates (provided by INP) are as follows: $18.0 \mathrm{~m}^{3} / \mathrm{h}$ in each of 17 type FA-1, $15.34 \mathrm{~m}^{3} / \mathrm{h}$ in each of 10 type FA-2, $4.19 \mathrm{~m}^{3} / \mathrm{h}$ in each of 51 water displacer tubes, and $4.319 \mathrm{~m}^{3} / \mathrm{h}$ in each of 7 irradiation tubes.

A number of parameters are monitored by the VVR-K operators and systems. Going above or below set point values generates an emergency protection action or scram to shut down the power production. Examples of these set points which are significant in the present analysis are as follows: power exceeding $7.2 \mathrm{MW}$ (i.e., $20 \%$ overpower); period less than $10 \mathrm{~s}$; total primary coolant flow less than $80 \%$ of nominal; and pool level dropping from 5.3 to $4.9 \mathrm{~m}$. There is a delay time of $0.3 \mathrm{~s}$ between crossing any of these set points and start of control rod motion for scram. The action of the 3 types of CR during scram was described in Section 3.5; as reminders, the KO rod critical positions differ for each cycle analyzed and the highest worth AZ rod is assumed stuck for all analyses. Coolant pumps continue to operate following scram unless the transient initiator is loss of pumping. When water level drops below $3.3 \mathrm{~m}$ the core emergency cooling system is activated, providing 10.4 and $10.0 \mathrm{~m}^{3} / \mathrm{h}$ water flow to 2 sets of spray headers.

Coolant flow is from top to bottom. Coolant flow rate is divided between the two channels based on the results obtained during the steady-state analysis. For VVR-K the peak clad temperature at steady state is always the interior of Tube 1 and, thus, the associated water is the gap between Tubes 1 and 2 . The coolant velocity in this gap at steady state is $2.44 \mathrm{~m} / \mathrm{s}$. This same value of velocity is input to the calculations for the average channel. The inlet coolant temperature and pressure are the same as used in the steady-state analyses (i.e., $45^{\circ} \mathrm{C}(318.15 \mathrm{~K})$ and $1.34 \mathrm{bar}$ ).

The initial $1 \mathrm{~s}$ of each transient calculated using PARET has constant boundary conditions in order to illustrate that the calculation is, indeed, at a steady state before the transient is imposed. The varying boundary conditions are imposed starting at $1 \mathrm{~s}$. This constancy is shown in the plots of results. In contrast, the RELAP5 runs start with a steady-state initialization which will be hidden from view; the RELAP5 results are plotted with a 1 s offset when comparing with PARET.

\subsection{Transient \#2: Shim Rod Withdrawal (KO)}

\subsubsection{Boundary Conditions}

The transient is initiated by assuming an inadvertent withdrawal of the highest worth shim rod with a speed of $0.4 \mathrm{~cm} / \mathrm{s}$. The specific shim rod and worth versus rod withdrawal position are different for each cycle analyzed and are shown in Table 2.5.3. The values in the table are converted to worth versus time using a constant rod speed of $0.4 \mathrm{~cm} / \mathrm{s}$. Inlet coolant temperature and flow rate are assumed constant during the transient. When scram occurs, the reactivity inserted by the falling CRs is reduced due to the assumed continued upward motion of the highest worth shim rod. 


\subsubsection{Results}

Key results calculated for this transient in the Cycle-1 core are shown in Figure 4.2.2.1; the top graph shows net reactivity, the middle graph shows reactor power, and the bottom graph shows peak cladding and coolant temperatures. Results are shown for RELAP5 and PARET. The reactivity insertion from KO rod motion starts at $1 \mathrm{~s}$, at which time power and temperatures start to increase. The reactor power reaches $7.2 \mathrm{MW}$ in $6.1 \mathrm{~s}$ after start of KO rod motion in RELAP5, which satisfies $20 \%$ overpower trip condition; after $0.3 \mathrm{~s}$ system delay for scram, the control rods start their insertion, which terminates the power increase. Peak cladding temperature is $100^{\circ} \mathrm{C}$ and peak coolant temperature is $78^{\circ} \mathrm{C}$, and these occur at time of peak power; after that time the temperatures decrease to values below those for steady state at full power. The increases in temperature are sufficiently small that no cladding damage would occur due to this transient. As shown in Figure 4.2.2.1, the results calculated using PARET are essentially the same as those calculated using RELAP5.

The results for the other cycles are shown in Figures 4.2.2.2 through 4.2.2.5; qualitatively the results are the same as for Cycle 1; therefore, only key values are highlighted here.

For Cycle 4, the power exceeds 7.2 MW at $5.1 \mathrm{~s}$ after start of $\mathrm{KO}$ withdrawal, the peak cladding temperature is $97^{\circ} \mathrm{C}$, and the peak coolant temperature is $76^{\circ} \mathrm{C}$.

For Cycle 10, the power exceeds $7.2 \mathrm{MW}$ at $4.4 \mathrm{~s}$ after start of $\mathrm{KO}$ withdrawal, the peak cladding temperature is $92^{\circ} \mathrm{C}$, and the peak

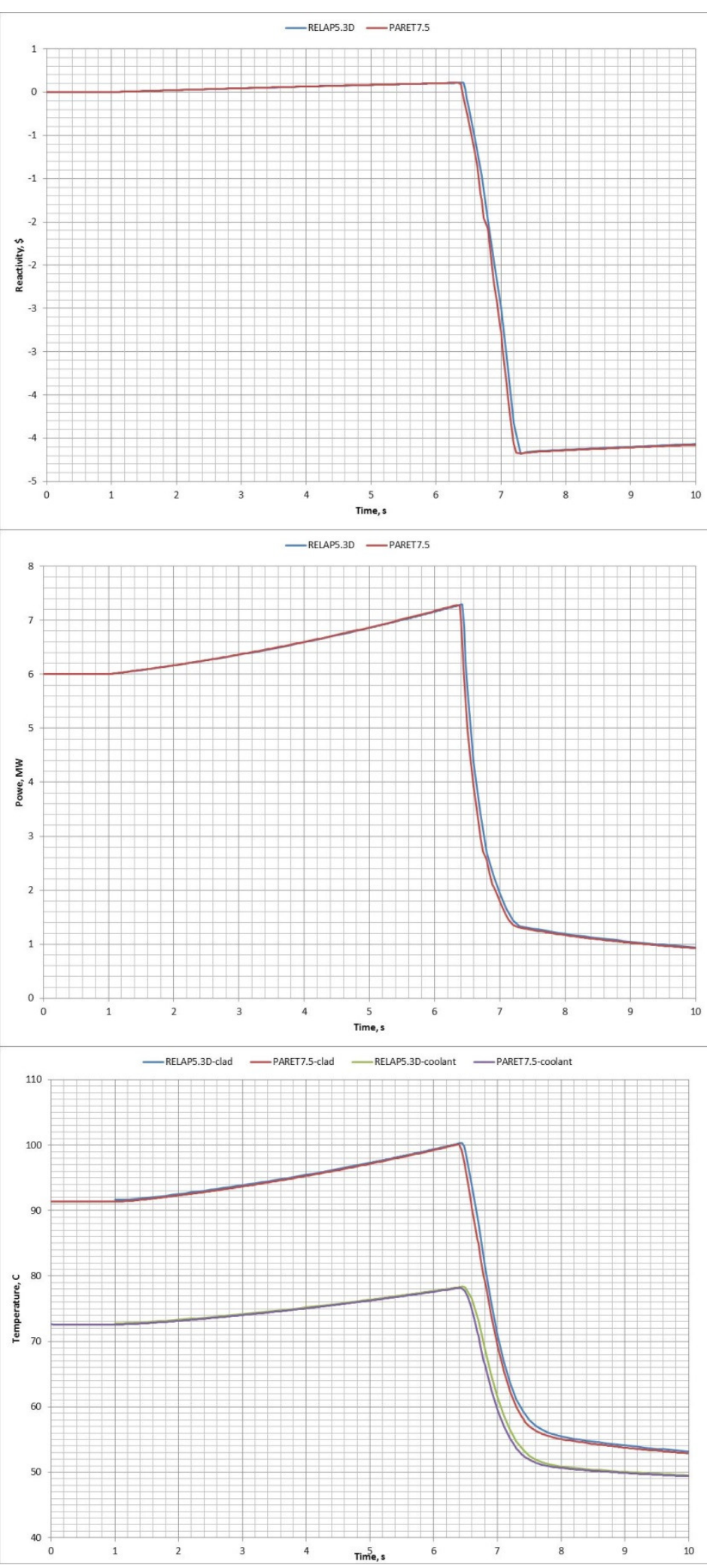

Figure 4.2.2.1 Results calculated for KO Transient in Cycle-1 Core 
coolant temperature is $72^{\circ} \mathrm{C}$.

For Cycle 12, the power exceeds $7.2 \mathrm{MW}$ at $4.6 \mathrm{~s}$ after start of $\mathrm{KO}$ withdrawal, the peak cladding temperature is $92^{\circ} \mathrm{C}$, and the peak coolant temperature is $71^{\circ} \mathrm{C}$.

For Cycle 15, the power exceeds $7.2 \mathrm{MW}$ at $4.9 \mathrm{~s}$ after start of $\mathrm{KO}$ withdrawal, the peak cladding temperature is $90^{\circ} \mathrm{C}$, and the peak coolant temperature is $69^{\circ} \mathrm{C}$.

As was true for steady state, the temperatures decrease for the higher cycle numbers analyzed. 


\section{For Verification Purposes Only}
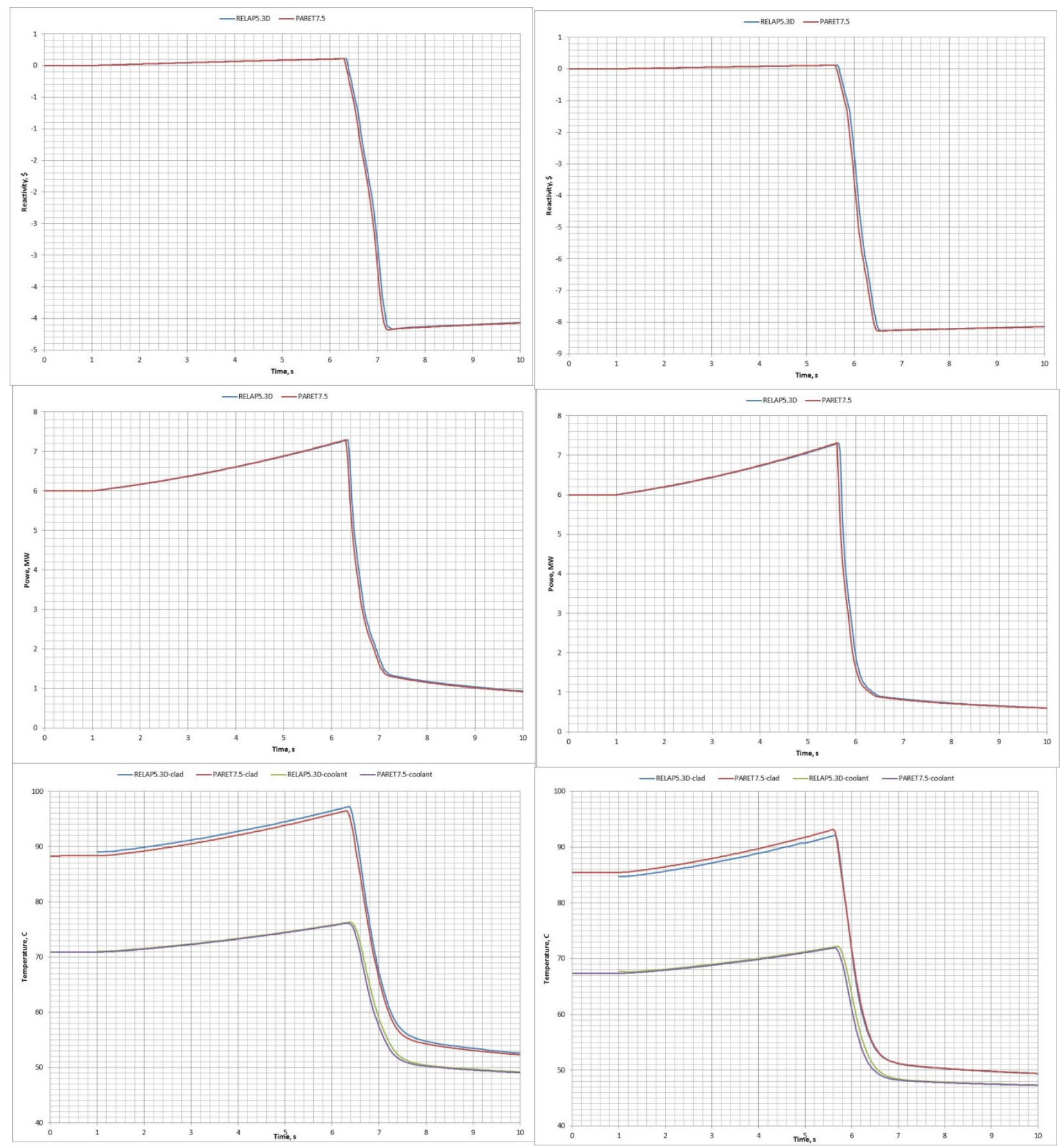

Figure 4.2.2.2 Results calculated for KO Transient in Cycle 4 Core

Figure 4.2.2.3 Results calculated for KO Transient in Cycle 10 Core 

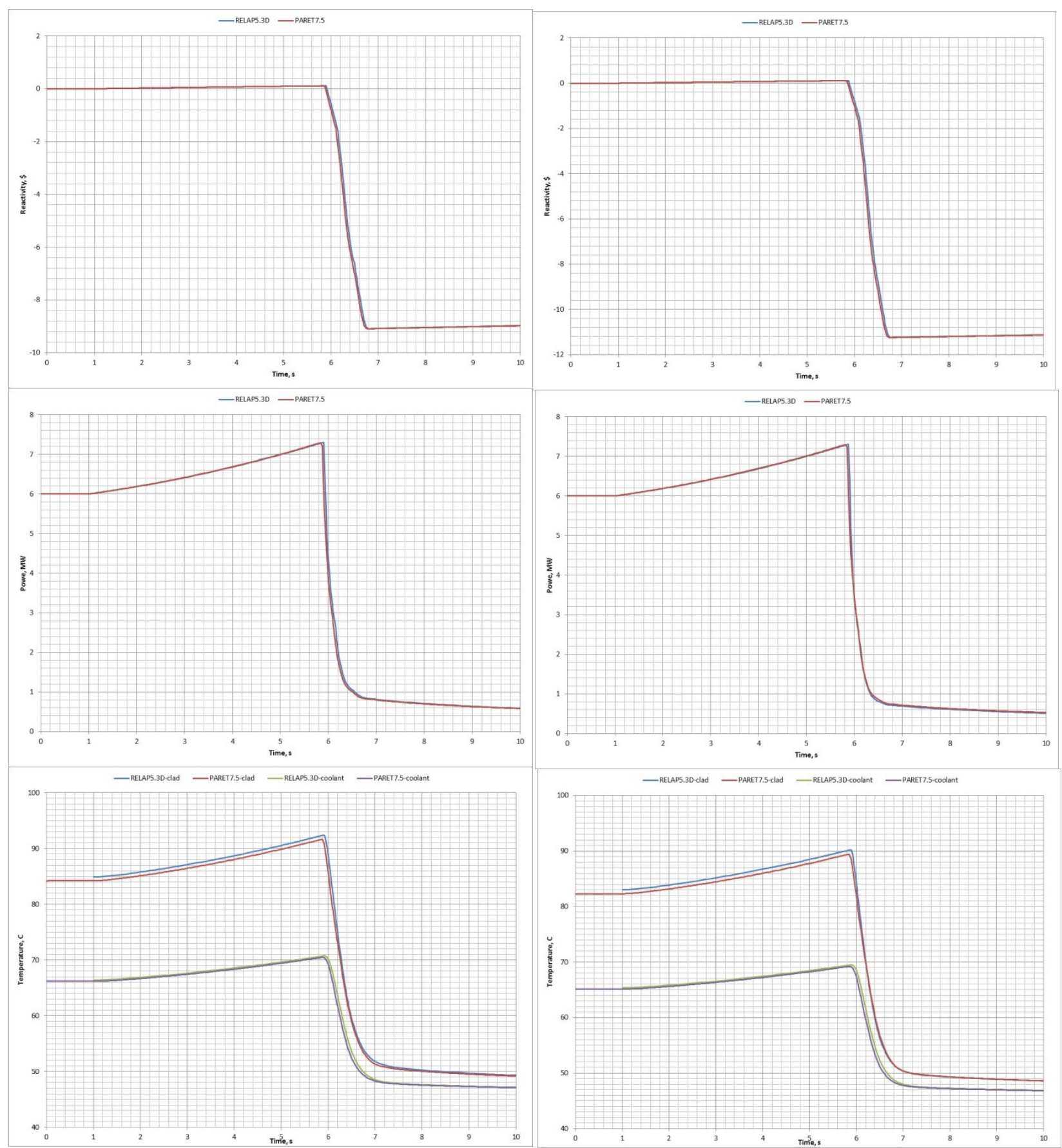

Figure 4.2.2.4 Results calculated for KO Transient in Cycle 12 Core

Figure 4.2.2.5 Results calculated for KO Transient in Cycle 15 Core 


\subsection{Transient \#3: Primary Pump Seizure (BLADE)}

\subsubsection{Boundary Conditions}

The transient is initiated by assuming a blade in one of the two primary pump breaks, stopping coolant flow through this pump; the coolant flow through this pump is assumed to decrease linearly to zero over $1 \mathrm{~s}$; the other primary pump continues to provide coolant flow at half of the total core nominal value. Inlet coolant temperature is assumed constant during the transient.

\subsubsection{Results}

Key results calculated for this transient in the Cycle-1 core are shown in Figure 4.3.2.1; the top graph shows coolant flow rate (normalized to 1 at steady state), the middle graph shows reactor power, and the bottom graph shows peak cladding and coolant temperatures. Results are shown for RELAP5 and PARET. The coolant flow rate decrease starts at $1 \mathrm{~s}$, at which time temperatures start to increase. Temperature increase leads to a power decrease due to the negative values for reactivity feedback coefficients. The coolant flow rate crosses $80 \%$ at $0.2 \mathrm{~s}$ after the start of flow decrease in RELAP5, which satisfies low flow trip condition; after $0.3 \mathrm{~s}$ system delay for scram, the control rods start their insertion, which cause the power to decrease even faster. Peak cladding temperature is $102^{\circ} \mathrm{C}$ and peak coolant temperature is $80^{\circ} \mathrm{C}$, and these occur $0.3 \mathrm{~s}$ after start of scram (or $0.8 \mathrm{~s}$ after start of flow decrease); after that time the temperatures decrease to values below those for steady state at full power and flow. The increases in temperature are sufficiently small that no cladding damage would occur due to this transient. As shown in Figure 4.3.2.1, the results calculated using PARET are essentially the same as those calculated using RELAP5.

The results for the other cycles are shown in Figures 4.3.2.2 through 4.3.3.5; qualitatively the results are the same as for Cycle 1; therefore, only key values are highlighted here. Coolant flow rate is not shown since it is the same for all cycles; the flow rate drops below $80 \%$ in $0.2 \mathrm{~s}$ and scram occurs $0.3 \mathrm{~s}$ later for all cycles analyzed. Although results are shown, the power history is essentially the same for all cycles analyzed.

For Cycle 4, the peak cladding temperature is $98^{\circ} \mathrm{C}$, and the peak coolant temperature is $78^{\circ} \mathrm{C}$.

For Cycle 10, the peak cladding temperature is $94^{\circ} \mathrm{C}$, and the peak coolant temperature is $74^{\circ} \mathrm{C}$.

For Cycle 12 , the peak cladding temperature is $94^{\circ} \mathrm{C}$, and the peak coolant temperature is $72^{\circ} \mathrm{C}$.

For Cycle 15 , the peak cladding temperature is $91^{\circ} \mathrm{C}$, and the peak coolant temperature is $71^{\circ} \mathrm{C}$.

As was true for steady state, the temperatures decrease for the higher cycle numbers analyzed. 


\section{For Verification Purposes Only}
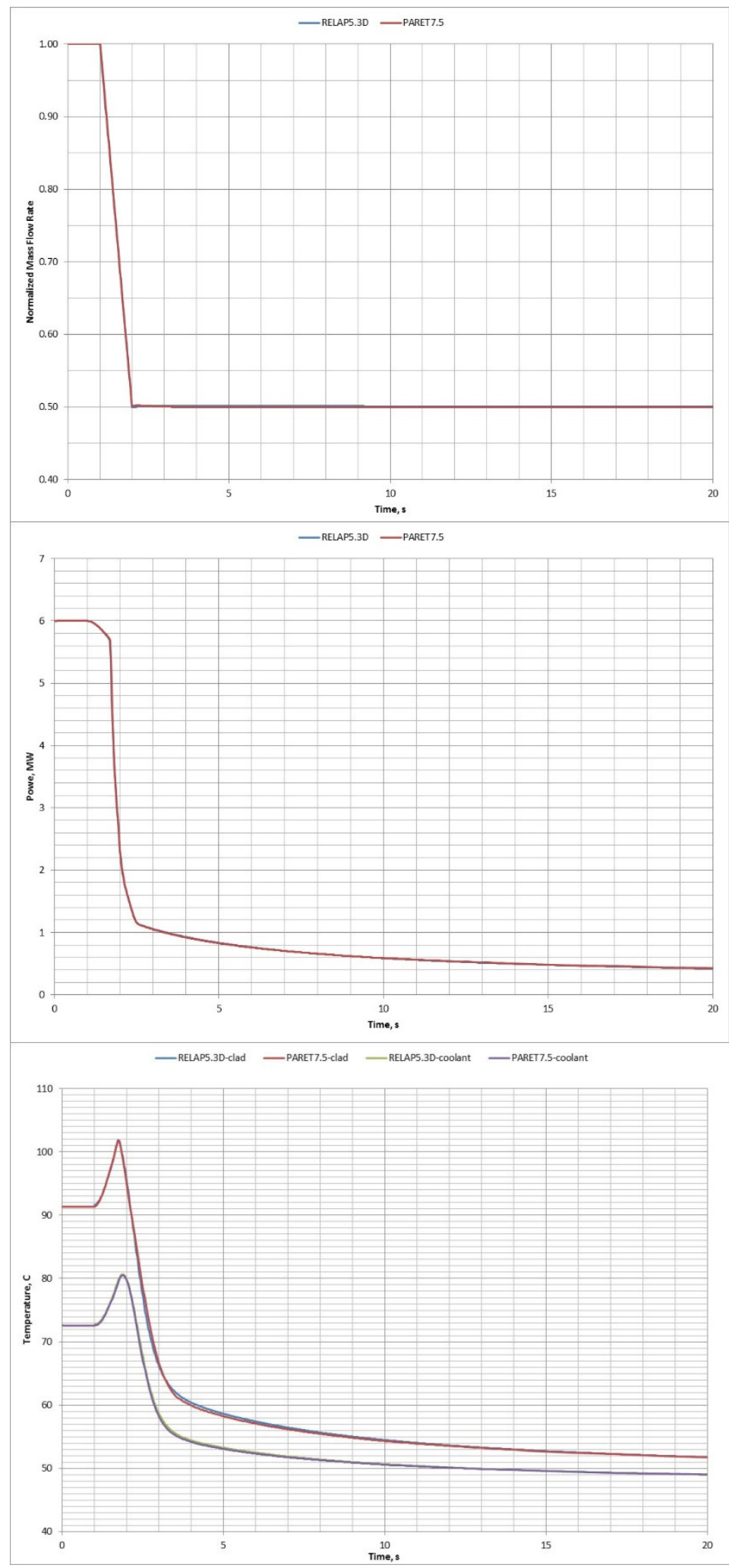

Figure 4.3.2.1 Results calculated for BLADE transient in Cycle 1 core 


\section{For Verification Purposes Only}
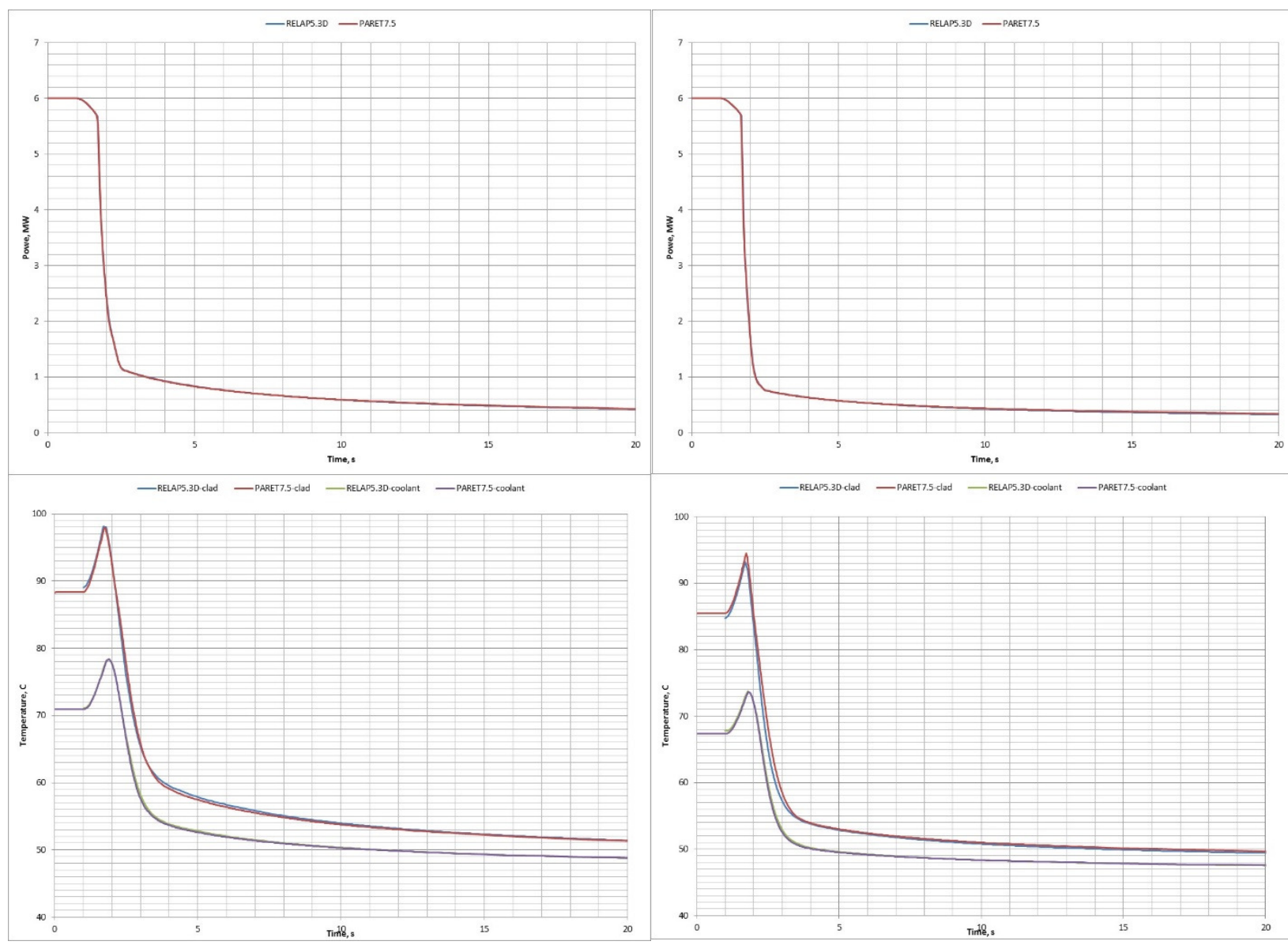

Figure 4.3.2.2 Results calculated for BLADE transient in Cycle 4 core

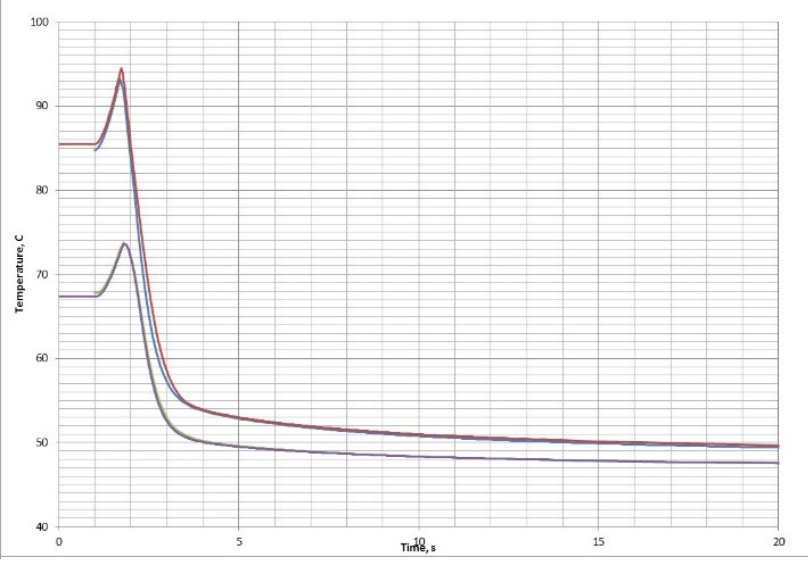

Figure 4.3.2.3 Results calculated for BLADE transient in Cycle 10 core 


\section{For Verification Purposes Only}
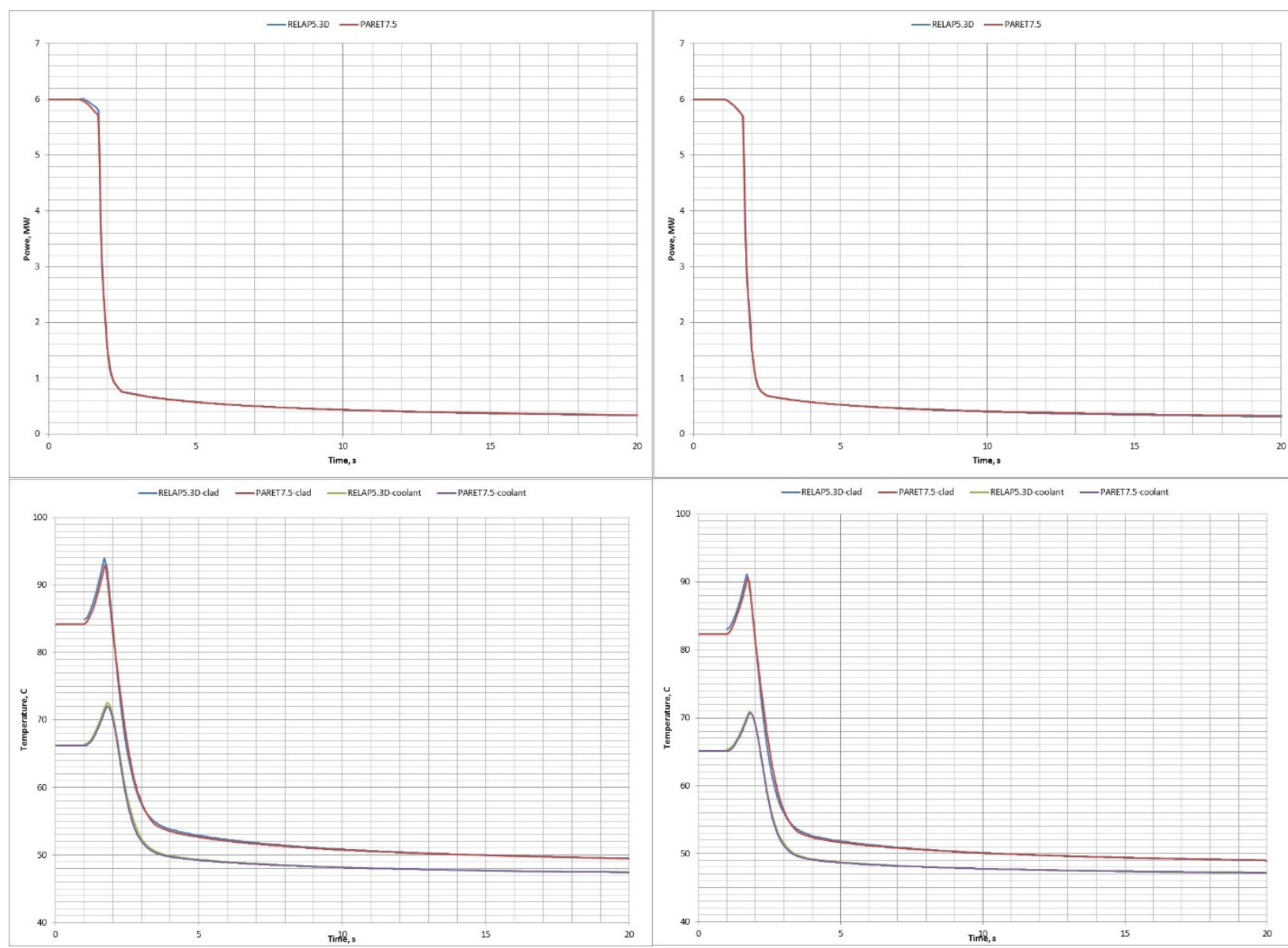

Figure 4.3.2.4 Results calculated for BLADE transient in Cycle 12 core

Figure 4.3.2.5 Results calculated for BLADE transient in Cycle 15 core 
For Verification Purposes Only

\subsection{Transient \#7: Loss of Offsite Electric Supply (LOOP)}

\subsubsection{Boundary Conditions}

The transient is initiated by assuming loss of offsite power. Loss of power means that both primary coolant pumps will stop; this is assumed to occur over $43.5 \mathrm{~s}$, as provided by INP [3]. Loss of offsite power will send a signal to automatically start one (or the other of two) diesel generators (DG) to supply emergency power to critical systems. Additionally there is an auxiliary primary coolant pump connected to uninterruptable power source (UPS) (as well as to DG). Therefore, primary coolant flow decreases from $700 \mathrm{~m}^{3} / \mathrm{hr}$ provided by two main primary coolant pumps to the $45 \mathrm{~m}^{3} / \mathrm{hr}$ provided by the auxiliary primary pump. The LOOP condition can be detected by the instrumentation and control system (ICS); it does not, however, cause immediate loss of power to CR drive magnets, since they are supplied by separate UPS; therefore, scram is not instantaneous. Although ICS can detect LOOP, scram will be due to decrease in primary coolant flow rate below $80 \%$; there is the normal $0.3 \mathrm{~s}$ delay between sensing an emergency condition and start of CR motion into the core. Inlet coolant temperature is assumed constant during the transient.

\subsubsection{Results}

Key results calculated for this transient in the Cycle-1 core are shown in Figure 4.4.2.1; the top graph shows coolant flow rate (normalized to 1 at steady state), the middle graph shows reactor power, and the bottom graph shows peak cladding and coolant temperatures. Results are shown for RELAP5 and PARET. The coolant flow rate decrease starts at $1 \mathrm{~s}$, at which time temperatures start to increase, which leads to power decrease due to the negative values for reactivity feedback coefficients. The coolant flow rate decrease below $80 \%$ at $6.42 \mathrm{~s}$ after start of flow decrease; CR start their movement into the core $0.3 \mathrm{~s}$ later. The temperatures reach maximum at time of scram $-99^{\circ} \mathrm{C}$ for peak cladding and $78^{\circ} \mathrm{C}$ for peak coolant. Thereafter, since power and coolant flow rate are decreasing at different rates, the temperatures will initially decrease, having minima of $54^{\circ} \mathrm{C}$ for peak cladding and $51^{\circ} \mathrm{C}$ for peak coolant at $13 \mathrm{~s}$ after start of transient. Subsequently, coolant flow rate is decreasing faster than the decrease in power; therefore, the temperatures start rising, having secondary maxima of $76^{\circ} \mathrm{C}$ for peak cladding and $68^{\circ} \mathrm{C}$ for peak coolant at $47 \mathrm{~s}$ after start of transient as calculated using RELAP5; these maxima are below steady-state values at full power and flow rate. Since coolant flow rate is now constant and power is continuing to decrease, the temperatures decrease from this time onward. The increases in temperature are sufficiently small that no cladding damage would occur due to this transient. As shown in Figure 4.4.2.1, the results calculated using PARET are essentially the same as those calculated using RELAP5; the secondary maximum in temperature calculated using PARET is 1 to $2^{\circ} \mathrm{C}$ lower than the values calculated using RELAP5; we consider this different to have no safety significance.

The results for the other cycles are shown in Figures 4.4.2.2 through 4.4.2.5; qualitatively the results are the same as for Cycle 1; therefore, only key values are highlighted here. Coolant flow rate is not shown since it is the same for all cycles. Scram occurs $0.3 \mathrm{~s}$ after sensing coolant flow less than $80 \%$ for all cycles analyzed. The power history is essentially the same for all cycles analyzed; therefore, the plots have been omitted. 
For Cycle 4, the peak cladding temperature has initial maximum of $96^{\circ} \mathrm{C}$, minimum of $54^{\circ} \mathrm{C}$, and secondary maximum of $75^{\circ} \mathrm{C}$. The peak coolant temperature has initial maximum of $76^{\circ} \mathrm{C}$, minimum of $50^{\circ} \mathrm{C}$, and secondary maximum of $67^{\circ} \mathrm{C}$.

For Cycle 10, the peak cladding temperature has initial maximum of $92^{\circ} \mathrm{C}$, minimum of $51^{\circ} \mathrm{C}$, and secondary maximum of $66^{\circ} \mathrm{C}$. The peak coolant temperature has initial maximum of $72^{\circ} \mathrm{C}$, minimum of $48^{\circ} \mathrm{C}$ and secondary maximum of $61^{\circ} \mathrm{C}$.

For Cycle 12, the peak cladding temperature has initial maximum of $91^{\circ} \mathrm{C}$, minimum of $51^{\circ} \mathrm{C}$, and secondary maximum of $66^{\circ} \mathrm{C}$. The peak coolant temperature has initial maximum of $70^{\circ} \mathrm{C}$, minimum of $48^{\circ} \mathrm{C}$, and secondary maximum of $60^{\circ} \mathrm{C}$.

For Cycle 15, the peak cladding temperature has initial maximum of $89^{\circ} \mathrm{C}$, minimum of $50^{\circ} \mathrm{C}$, and secondary maximum of $64^{\circ} \mathrm{C}$. The peak coolant temperature has initial maximum of $69^{\circ} \mathrm{C}$, minimum of $48^{\circ} \mathrm{C}$, and secondary maximum of $58^{\circ} \mathrm{C}$.

As was true for steady state, the temperatures decrease for the higher cycle numbers analyzed.
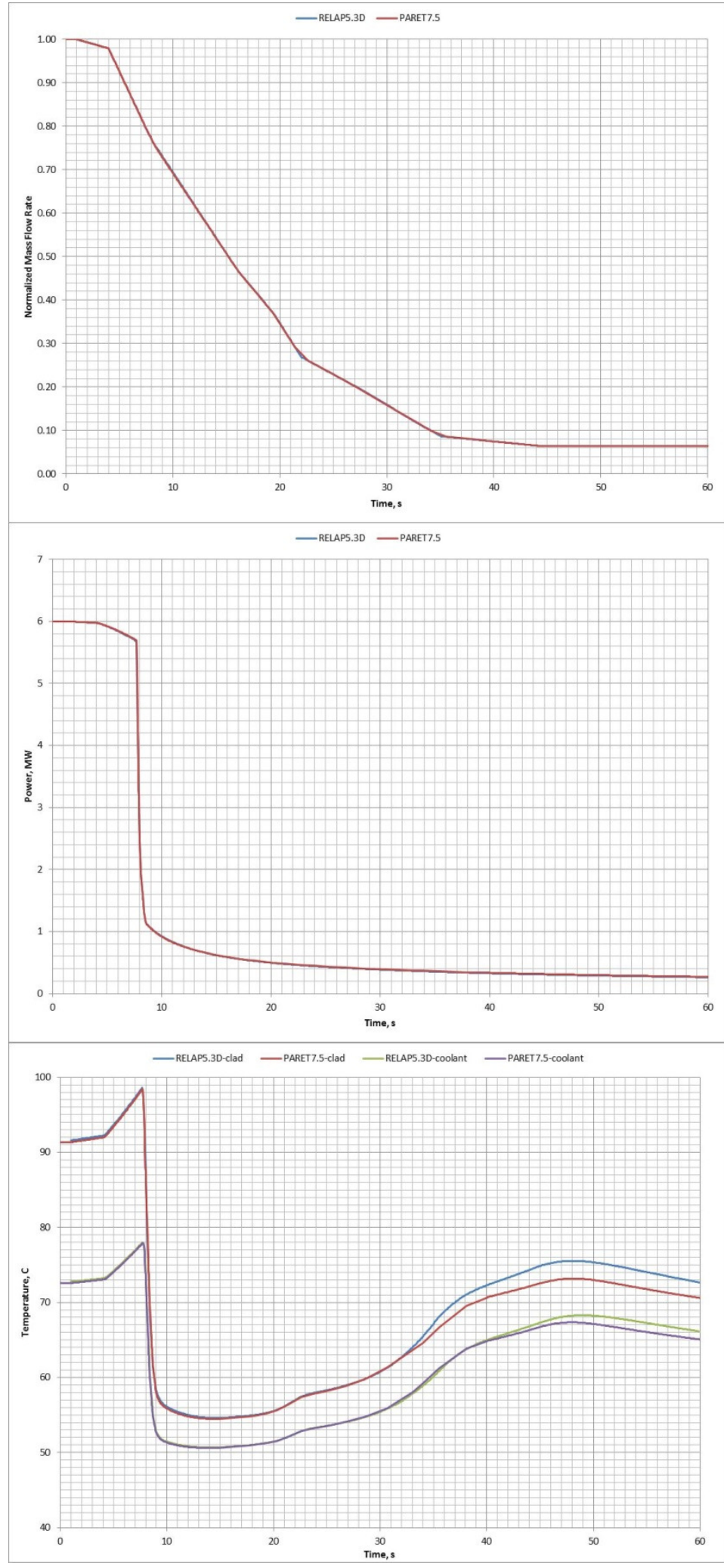

Figure 4.4.2.1 Results calculated for LOOP transient in Cycle 1 core 


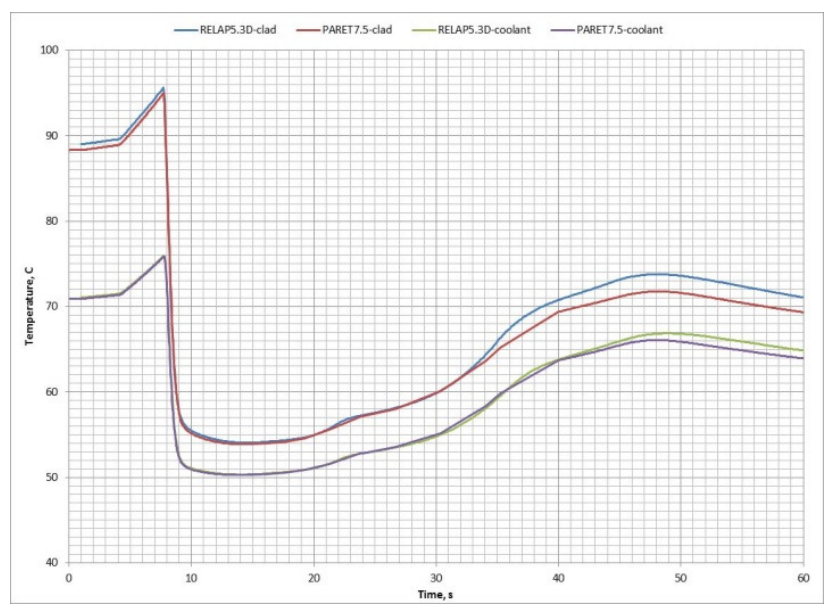

Figure 4.4.2.2 Results calculated for LOOP transient in Cycle 4 core

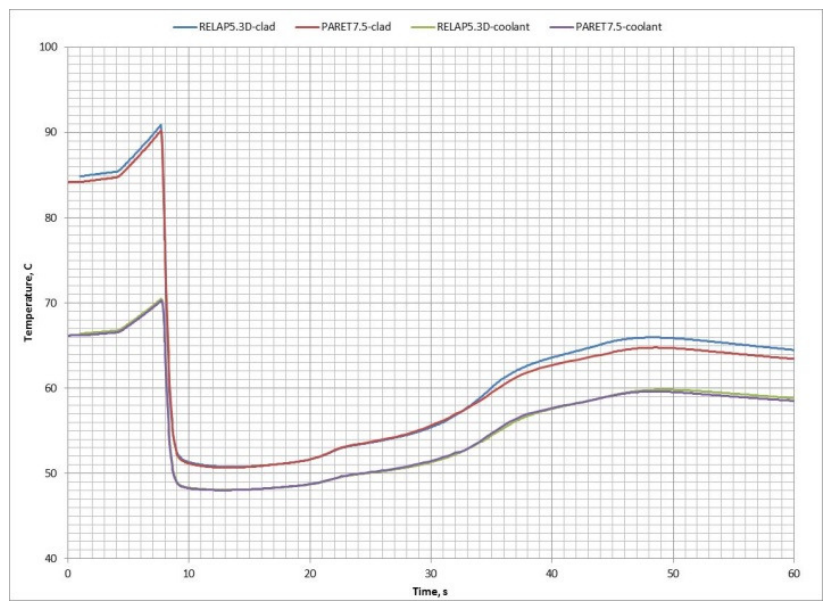

Figure 4.4.2.4 Results calculated for LOOP transient in Cycle 12 core

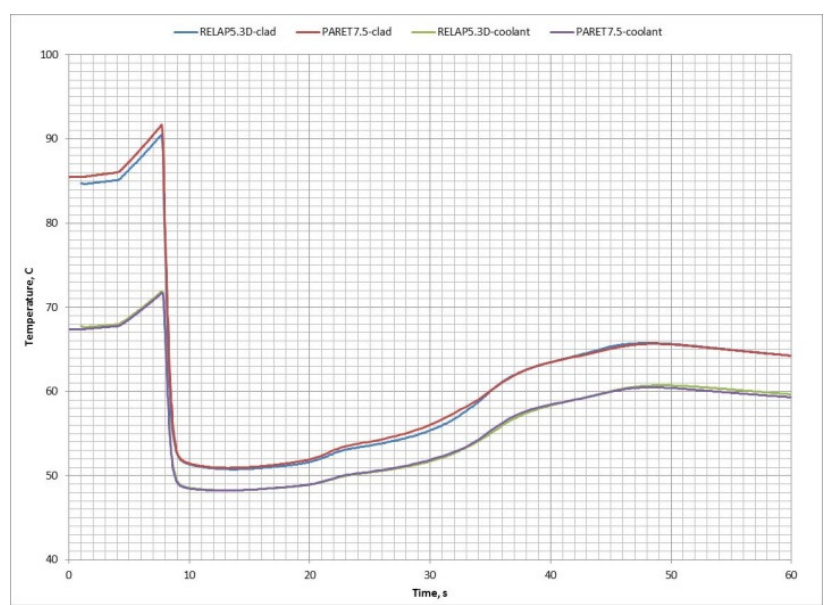

Figure 4.4.2.3 Results calculated for LOOP transient in Cycle 10 core

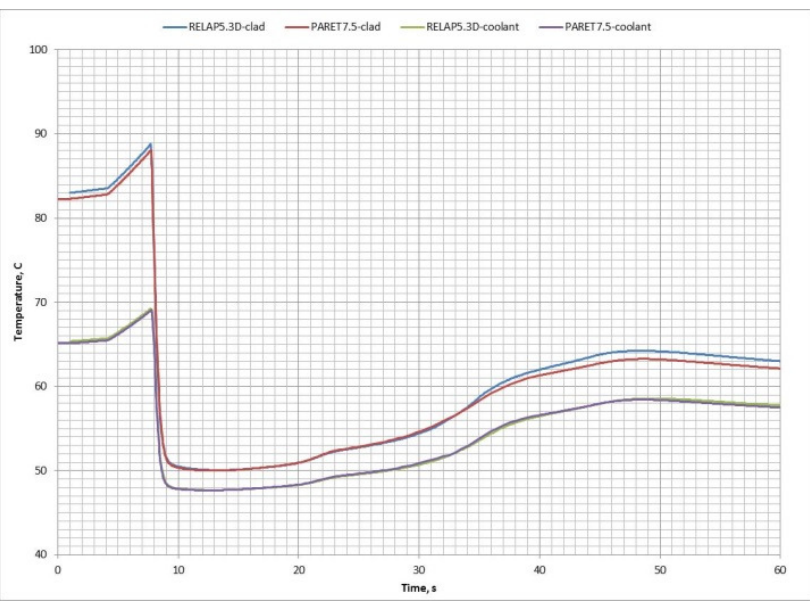

Figure 4.4.2.5 Results calculated for LOOP transient in Cycle 15 core 


\subsection{Transient \#9: Impact of Experiments (EXP)}

\subsubsection{Boundary Conditions}

The transient is initiated by assuming an unspecific failure of the mounting for an experiment in the reactor that inserts reactivity of $1.5 \%$ in $1 \mathrm{~s}$. The reactivity inserted in percent is the same for all cores; however, the value must be converted to dollars for input to the RELAP5 and PARET codes; since $\beta_{\text {eff }}$ is different for each core (see Table 2.5.1), the reactivity inserted in dollars is different for each core, ranging from $1.95 \$$ for Cycle 1 to $2.17 \$$ for Cycle 15 . Inlet coolant temperature and flow rate are assumed constant during the transient.

\subsubsection{Results}

Key results calculated for this transient in the Cycle-1 core are shown in Figure 4.5.2.1; the top graph shows reactor power and the bottom graph shows peak cladding and coolant temperatures. Results are shown for RELAP5 and PARET; the RELAP5 results are discussed first. The reactivity insertion from EXP motion starts at $1 \mathrm{~s}$, at which time power and temperatures start to increase. Reactor period is below the $10 \mathrm{~s}$ trip condition almost immediately; scram occurs $0.3 \mathrm{~s}$ later, at which time the reactor power reaches $12.6 \mathrm{MW}$; power then rapidly decreases due insertion of the control rods. Peak cladding surface temperature is $112^{\circ} \mathrm{C}$ and peak coolant temperature is $87^{\circ} \mathrm{C}$, and these occur slightly after peak reactor power; after that time the temperatures decrease to values below those for steady state at full power. The increases in temperature are sufficiently small that no cladding damage would occur due to this transient. As shown in Figure 4.5.2.1, the results calculated using PARET are essentially the same as those calculated using RELAP5; the only noticeable difference is that the peak cladding temperature is slightly $\left(2^{\circ} \mathrm{C}\right)$ higher using PARET than using RELAP5.

The older version of PARET being used by INP does not have built-in capability for trip on low period (although it could be simulated by inputting the power level at which the low period occurs). The INP calculation was performed using $20 \%$ overpower trip. ANL has performed the calculation in this mode for Cycle 1, and the results are shown in Figure 4.5.2.2. The RELAP5 results are discussed first. Reactor power crosses the $7.2 \mathrm{MW}$ trip condition $0.1 \mathrm{~s}$ after start of reactivity insertion. Scram occurs $0.3 \mathrm{~s}$ later, at which time reactor power reaches $17.4 \mathrm{MW}$; power then rapidly decreases due insertion of the control rods. Peak cladding surface temperature is $126^{\circ} \mathrm{C}$ and peak coolant temperature is $99^{\circ} \mathrm{C}$, and these occur slightly after peak reactor power; after that time the temperatures decrease to values below those for steady state at full power. The extra $0.1 \mathrm{~s}$ of operation before scram in the power trip versus period trip case leads to noticeably larger peak power and temperatures; however, the increases in temperature are sufficiently small that no fuel damage would occur due to this transient. As shown in Figure 4.5.2.2, the results calculated using PARET are essentially the same as those calculated using RELAP5; the only noticeable difference is that the peak cladding temperature is somewhat $\left(5^{\circ} \mathrm{C}\right)$ higher using PARET than using RELAP5.

Since the low period trip will occur before the high power trip, the additional cycles were calculated at ANL using the low period trip, which occurs essentially instantaneously for all cycles. The results for the other cycles are shown in Figures 4.5.2.3 through 4.5.2.6; qualitatively the results are the same as for Cycle 1; therefore, only key values are highlighted here. 
For Cycle 4, the peak power is $12.8 \mathrm{MW}$ at scram ( $0.3 \mathrm{~s}$ after start of EXP motion), the peak cladding temperature is $110^{\circ} \mathrm{C}$, and the peak coolant temperature is $85^{\circ} \mathrm{C}$.

For Cycle 10, the peak power is $13.3 \mathrm{MW}$ at scram ( $0.3 \mathrm{~s}$ after start of EXP motion), the peak cladding temperature is $105^{\circ} \mathrm{C}$, and the peak coolant temperature is $78^{\circ} \mathrm{C}$.

For Cycle 12, the peak power is $13.2 \mathrm{MW}$ at scram ( $0.3 \mathrm{~s}$ after start of EXP motion), the peak cladding temperature is $105^{\circ} \mathrm{C}$, and the peak coolant temperature is $76^{\circ} \mathrm{C}$.

For Cycle 15, the peak power is $13.6 \mathrm{MW}$ at scram ( $0.3 \mathrm{~s}$ after start of EXP motion), the peak cladding temperature is $103^{\circ} \mathrm{C}$, and the peak coolant temperature is $76^{\circ} \mathrm{C}$.

As was true for steady state, the temperatures decrease for the higher cycle numbers analyzed. There is no important difference among the results for Cycles 10, 12, and 15. 


\section{For Verification Purposes Only}
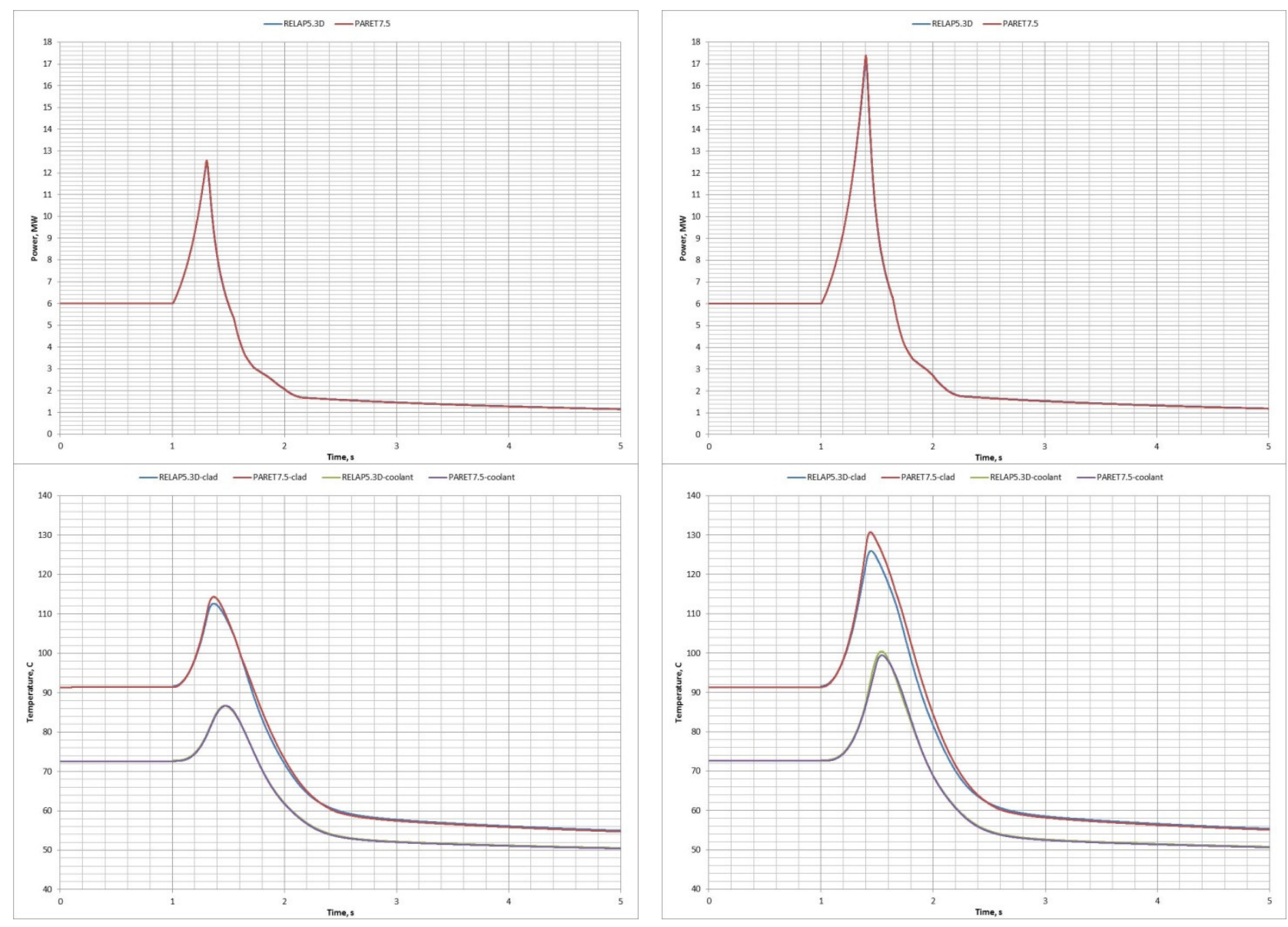

Figure 4-5.2.1 Results calculated for EXP transient with low period trip in Cycle 1 core

Figure 4-5.2.2 Results calculated for EXP transient with high power trip in Cycle 1 core 


\section{For Verification Purposes Only}
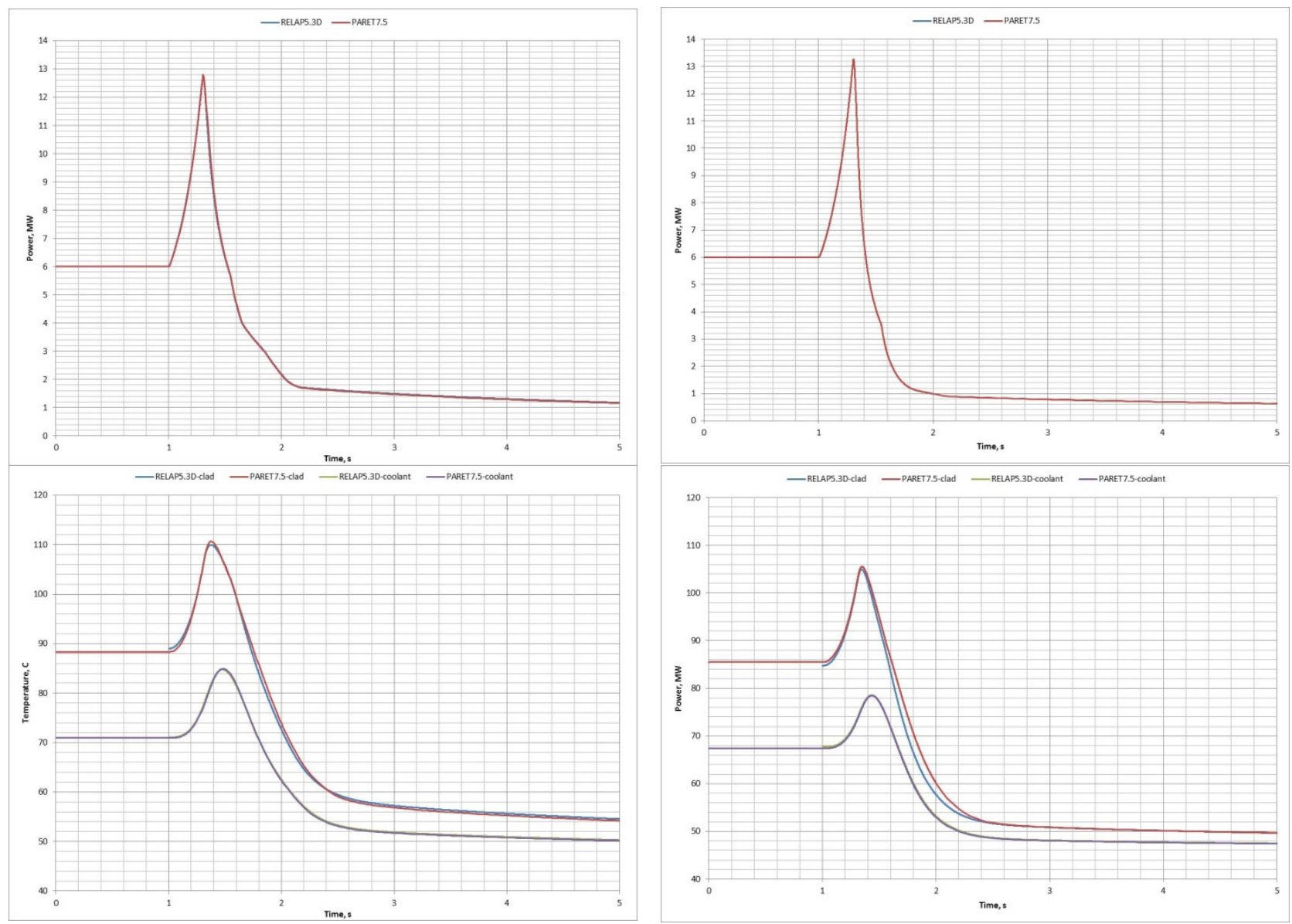

Figure 4.5.2.3 Results calculated for EXP transient with low

Figure 4.5.2.4 Results calculated for EXP transient with low period trip in Cycle 4 core period trip in Cycle 10 core 


\section{For Verification Purposes Only}
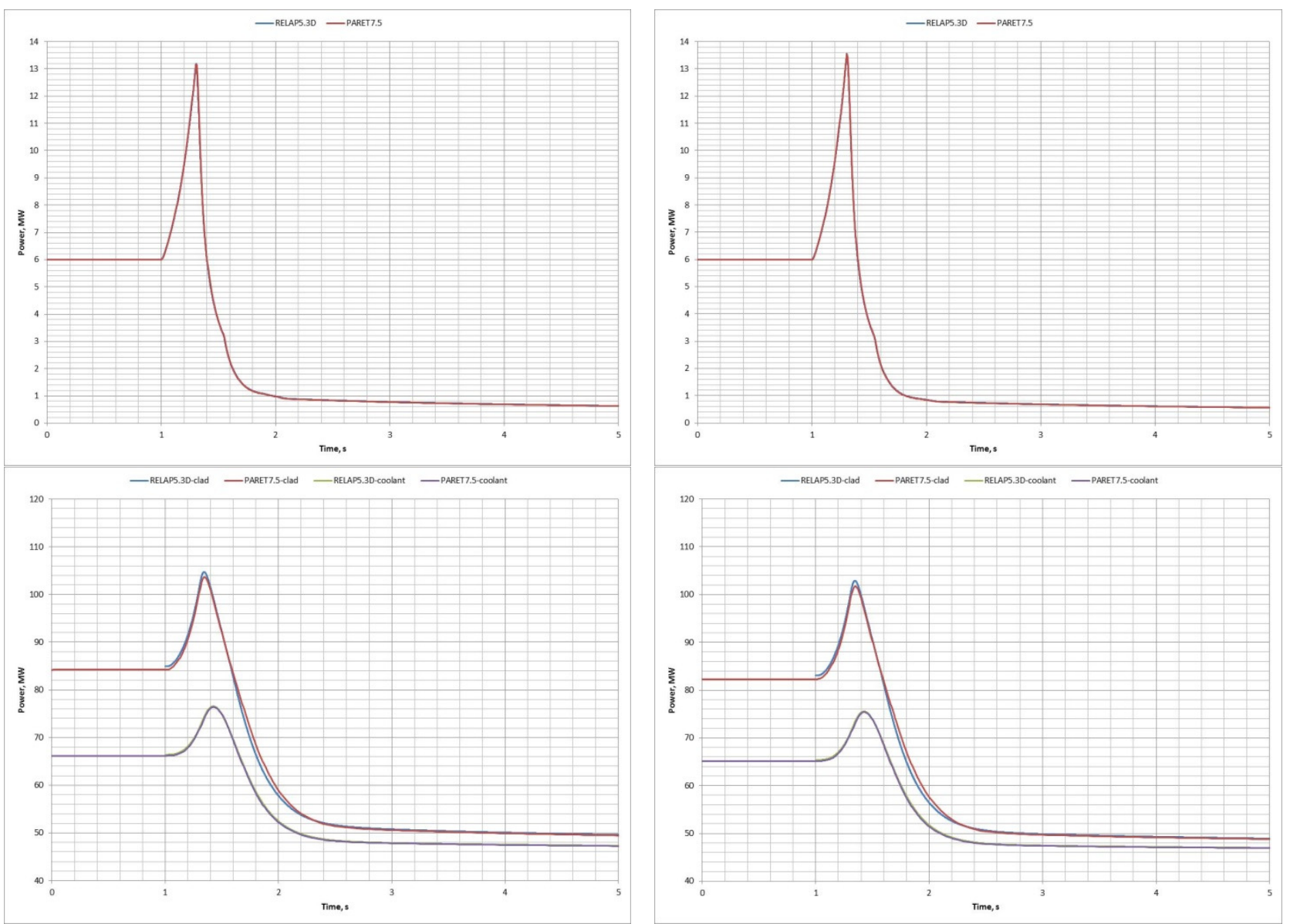

Figure 4-5.2.5 Results calculated for EXP transient with low period trip in Cycle 12 core

Figure 4 5.2.6 Results calculated for EXP transient with low period trip in Cycle 15 core 


\subsection{Transient \#5: Loss of Primary Coolant (LOCA)}

\subsubsection{Boundary Conditions}

As specified by INP, the initiator is complete breakage of the primary coolant inlet and outlet pipes. The exact breakage location is not specified. It is assumed that the worst place to break either pipe is just below the point where the pipe connects to the bottom of the reactor vessel. It is also assumed that the full flow area of the pipe is available for the unobstructed flow of coolant out of the reactor vessel. The mechanism leading to pipe breakage is seismic. There are a series of responses as this accident progresses.

Reactor scram will be initiated due to one or more of the following safety system settings being crossed: primary pressure in head pipeline decrease to $0.243 \mathrm{MPa}$, primary coolant flow decrease by $20 \%$, or central tank water level decrease by $0.4 \mathrm{~m}$. INP indicates that $20 \%$ coolant flow reduction will occur first, within $1 \mathrm{~s}$ of pipe break.

The initial water level in the reactor vessel is $5.3 \mathrm{~m}$. Decrease of water level to $3.3 \mathrm{~m}$ automatically causes valve changes to allow flow of water to core spray systems. There are two core water spray systems: upper and lower. For each system, water initially flows by gravity from a supply tank to a set of spray nozzles; the water supply tanks can be refilled using several methods. The lower system has its spray nozzles $200 \mathrm{~mm}$ above the core; its water supply is a set of four $10 \mathrm{~m}^{3}$ tanks; flow rate is $10.0 \mathrm{~m}^{3} / \mathrm{h}$; the initial volume of water will be exhausted in $3.8 \mathrm{~h}$. The upper system has its spray nozzles at the top of the reactor vessel; its water supply is a single $80 \mathrm{~m}^{3}$ tank; flow rate is $10.4 \mathrm{~m}^{3} / \mathrm{h}$; the initial volume of water will be exhausted in $7.7 \mathrm{~h}$.

The water level dropping to $2.9 \mathrm{~m}$ generates signal to start two diesel-generators and turn on two core spray pumps which are supplied by the diesel-generators. There is one pump for each of the two spray headers. Each pump has capacity of $10 \mathrm{~m}^{3} / \mathrm{h}$. Each pump connects pit under reactor tank to one of the two spray headers. The pit has volume of $37.5 \mathrm{~m}^{3}$; if pit is not resupplied with water, one pump will empty the pit in $3.8 \mathrm{~h}$ and two pumps will empty pit in $1.9 \mathrm{~h}$. Power to pumps can also be supplied by newly installed uninterruptible power supply, intended to meet specification of $50 \mathrm{~kW}$ for at least $5 \mathrm{~h}$.

The goal of either of these two supplies of emergency spray system water is to provide sufficient water on surface of fuel elements to remove the decay-level of power generation and prevent the fuel from being damaged (e.g., stay below melting temperature). This cooling process may change part of the liquid water to water vapor (i.e., steam).

The PARET code is not able to compute transient progression of the loss-of-coolant accident (LOCA). The RELAP5 code, in theory, has this capability but would require development of a much more extensive model of the VVR-K reactor than was required for the analyses performed for the other transients and shown in Sections 4.2-4.5. It is important to note that the information required to generate this RELAP5 model is not available and also that a detailed analysis of this "external event seismic" is not part of this verification analysis. Two aspects of the LOCA can be analyzed on an approximate basis using other techniques: (1) estimate the time to empty the reactor vessel and (2) 
estimate the minimum flow rate of water (through the spray devices) required to remove heat from the core after draining.

\subsubsection{Results: Vessel Emptying Time}

A Bernoulli-type approach shows that the velocity $\mathrm{V} 3$ of water exiting a hole in the bottom of a large diameter tank of water is

$$
\mathrm{V} 3=(2 * \mathrm{~g} * \mathrm{H} 1)^{0.5},
$$

where $g$ is the acceleration due to gravity $\left(9.8 \mathrm{~m} / \mathrm{s}^{2}\right)$ and $\mathrm{H} 1$ is the height of water above the hole. (Note that the accuracy of this equation decreases as the water height decreases.) The nominal height of water in the VVR-K reactor vessel is about $5.3 \mathrm{~m}$; the corresponding exit velocity is $10.2 \mathrm{~m} / \mathrm{s}$. The exit hole is two $0.35 \mathrm{~m}$ diameter primary coolant pipes (one inlet and one outlet) having a flow area S3 of $0.0962 \mathrm{~m}^{2}$ per pipe or $0.1924 \mathrm{~m}^{2}$ total; coolant is therefore leaving the reactor vessel at an initial rate of $1.96 \mathrm{~m}^{3} / \mathrm{s}$ (or $7060 \mathrm{~m}^{3} / \mathrm{h}$ which is about 10 times the normal primary coolant flow rate of $700 \mathrm{~m}^{3} / \mathrm{h}$ ). The water loss rate would decrease in time as the water level decreases; this decrease is neglected in this analysis; using the highest water loss rate is a conservative approach in terms of safety analysis since it gives shorter times for vessel emptying.

The reactor vessel is $2.3 \mathrm{~m}$ in diameter. When the water level drops $0.4 \mathrm{~m}$ (i.e., to a level of $4.9 \mathrm{~m}$ ), a trip signal will be generated on low water level; this will occur in $0.85 \mathrm{~s}$ if the loss rate is $1.96 \mathrm{~m}^{3} / \mathrm{s}$. When the water level drops to $3.3 \mathrm{~m}$, the spray system is activated with gravity flow from supply tanks; this will occur in $4.25 \mathrm{~s}$ if the water loss rate is $1.96 \mathrm{~m}^{3} / \mathrm{s}$. When the water level drops to $2.9 \mathrm{~m}$, the diesel-generator and spray pumps are activated to supply water from pit under reactor vessel to the spray headers; this will occur in $5.1 \mathrm{~s}$ if the water loss rate is $1.96 \mathrm{~m}^{3} / \mathrm{s}$. Core uncovery starts when water level has decreased by $3.6 \mathrm{~m}$ (i.e., water level of $1.7 \mathrm{~m}$ ); this will occur in $7.6 \mathrm{~s}$ if the loss rate is $1.96 \mathrm{~m}^{3} / \mathrm{s}$.

With fuel uncovery starting so quickly, systems must act automatically (as they are designed to do) in order to provide emergency cooling to the core when required. Note that the initial water loss rate of about $7060 \mathrm{~m}^{3} / \mathrm{h}$ is 346 times larger than the $20.4 \mathrm{~m}^{3} / \mathrm{h}$ rate for the combination of the two core spay systems. Therefore, an unobstructed flow break of both primary coolant pipes will lead to core uncovery - the emergency sprays do not provide refill of the vessel, merely a cooling mechanism.

\subsubsection{Results: Shutdown Core Cooling}

After loss of normal coolant from the core a shower cooling of FA is provided by a film of water which is flowing down on the surface of the fuel elements. When this film is present the temperature of fuel elements differs slightly from the temperature of boiling water. When there is insufficient flow of water down on fuel elements the water evaporates before reaching the bottom of the FA; thus the lower part of fuel elements will be cooled only by steam (i.e., water vapor) and can heat up to higher temperature.

The minimum flow of water required for a given energy release is defined by equality of energy generation in FA and heat absorbed by the flow of falling water in the FA. The heating of water is from its temperature at inlet to FA up to temperature of saturation, and then additional energy is absorbed causing evaporation of water to form steam. The case of full vaporization corresponds to the minimum water supply. The energy balance may be expressed as 


$$
G_{\min }=Q /\left\{N *\left[C_{p}^{*}\left(T_{s a t}-T_{i n}\right)+h_{f g}\right]\right\}
$$

where $G_{\min }$ is the minimum mass flow rate $[\mathrm{kg} / \mathrm{s}]$ of water required to cool one $F A, Q$ is the core power $[W], N$ is the number of FAs, $C_{p}$ is the specific heat capacity $[4.18 \mathrm{~kJ} / \mathrm{kg}-\mathrm{C}]$ of liquid water, $\mathrm{T}_{\text {sat }}$ and $\mathrm{T}_{\text {in }}$ are the saturation $\left[100^{\circ} \mathrm{C}\right.$, assuming atmospheric pressure everywhere in reactor vessel] and inlet $\left[45^{\circ} \mathrm{C}\right]$ temperature of water, respectively, and $h_{\mathrm{fg}}$ is the heat of vaporization $[2.257 \mathrm{MJ} / \mathrm{kg}]$ of water.

The rapidly decreasing water level will generate a trip $0.85 \mathrm{~s}$ after the pipe break; therefore, the reactor will be at decay power when the spray cooling starts a few seconds later. The relative core power after 20-day ( 1 cycle) operation (Eq. 18 of [12]) is $5.6 \%$ after $1 \mathrm{~s}, 5.1 \%$ after $7.5 \mathrm{~s}, 4.7 \%$ after $15 \mathrm{~s}$, and $1 \%$ after about 3 hours. For illustration, the required coolant flow will be based on the power at $7.5 \mathrm{~s}-$ i.e., the time at which core uncover starts; from Eq. 4.6.3.1 one can see that the coolant flow scales linearly with core power, so that less coolant flow is required at later times. The specific numbers from here onward depend on the specific core.

The analysis for the Cycle 1 LEU core will be presented first as the method is explained. This will be followed by a single paragraph for the other LEU cycles.

The first LEU core has a nominal power of $6 \mathrm{MW}$; there are 17 8-tube fuel assemblies and 105 -tube fuel assemblies. As shown in Table 2.6.1 the average power for the 8-tube FA is $256.2 \mathrm{~kW}$ and for the 5-tube FA is $164.5 \mathrm{~kW}$ One must be able to cool the peak power FA not just the average FA. Neutronic analysis of the core shows that peak power FA is $409 \mathrm{~kW}$ in $6 \mathrm{MW}$ core; the decay power in the peak power FA at $7.5 \mathrm{~s}$ is $20.9 \mathrm{~kW}$, which is one choice for " $\mathrm{Q} / \mathrm{N}$ " in the above equation.

Note that the heat of vaporization dominates the denomination of Eq. 4.6.3.2 because we have assumed full vaporization of the water. For this core, the flow rate required to cool 1 peak power $F A$ is $0.0084 \mathrm{~kg} / \mathrm{s}$ or $0.030 \mathrm{~m}^{3} / \mathrm{h}$ (using liquid water density of $991 \mathrm{~kg} / \mathrm{m}^{3}$ at $45^{\circ} \mathrm{C}$ ).

Look at the spray flow, which is stated to be $10.0 \mathrm{~m}^{3} / \mathrm{h}$ from lower and $10.4 \mathrm{~m}^{3} / \mathrm{h}$ from upper or $20.4 \mathrm{~m}^{3} / \mathrm{h}$ when combined. A certain portion of the spray water is assumed to go somewhere other than the core barrel area (due to divergence of spray from nozzle); this is assumed to be $20 \%$; this leaves $80 \%$ or $16.3 \mathrm{~m}^{3} / \mathrm{h}$ spray flow into interior of core barrel. It is important to note that new sprays are being installed in the reactor and their location can be designed in such a way that less than $20 \%$ is lost outside the core (as assumed here).

Assume that within the core barrel the distribution of spray water is uniform; thus each FA gets an amount of flow based on its total (not flow) cross sectional area (hexagon set on flat-to-flat pitch $68.3 \mathrm{~mm}$, or $0.00404 \mathrm{~m}^{2}$ ) relative to the total cross sectional area in the core barrel (circle with $0.745 \mathrm{~m}$ diameter, or $0.436 \mathrm{~m}^{2}$ area), which is an area factor of 0.0093 . Multiply by $16.3 \mathrm{~m}^{3} / \mathrm{h}$ flow to core barrel gives $0.151 \mathrm{~m}^{3} / \mathrm{h}$ to $1 \mathrm{FA}$. This exceeds the required flow of $0.030 \mathrm{~m}^{3} / \mathrm{h}$ by a factor of 5.0 .

Since the peak FA power is lower for the other cycles analyzed (i.e., 389, 348, 335, and $308 \mathrm{~kW}$ in $6 \mathrm{MW}$ core at steady state from Table 2.6.1), the amount of cooling required is lower than for Cycle 1.

Based on the foregoing lumped-parameter estimate and assumptions invoked, the $20.4 \mathrm{~m}^{3} / \mathrm{h}$ water flow from the two emergency spray systems is sufficient to remove decay heat from the fuel. 


\subsubsection{Results: Cautions}

The preceding analysis is only an estimate. There are a number of assumptions and limitations. These are enumerated below.

a. Uniformity of spray is an assumption. Under Task 13.2 of Work Order 13, INP is to design, manufacture, install, and test new spray headers; perhaps INP can use that opportunity to provide better guidance regarding distribution of core spray flow.

b. There is no examination of the actual heat transfer process between the fuel and the water. For example, what is the heat transfer coefficient and what is the resulting fuel surface temperature?

c. If the water does not fully vaporize, then a higher coolant flow rate will be required to remove the same amount of heat.

d. Vaporizing water (even some of it) produces steam which wants to flow upward due to buoyancy and will inhibit the downward flow of liquid water between the fuel tubes. If steam up flow is sufficiently fast it can totally prevent down flow of liquid, a situation known as "flooding" or "counter current flow limitation". Supplying additional spray water does not necessarily eliminate this phenomenon.

e. In a transient analysis, the fuel could be allowed to heat somewhat during the early part of the LOCA (as long as the fuel does not exceed its structural integrity limit) and then show decreasing temperature as decay power decreases and coolant flow is maintained.

f. Fortunately, less water is needed as time gets longer since decay power continues to decrease.

A more detailed analysis could be useful.

\subsection{Transients Summary}

Analysis of four transients (shim rod withdrawal, primary pump seizure, loss of offsite electric supply, and impact of experiments) using the RELAP5 code indicates that built-in safety systems automatically act quickly on high power, low coolant flow, or low reactor period signals to shut down the VVR-K reactor before there can be any significant cladding damage. In general, the Cycle 1 core presents the highest peak FA power and highest material temperatures of the cycles analyzed. Essentially identical results were obtained for these transients using the PARET code. A fifth transient (loss of primary coolant) was analyzed in an approximate manner with many simplifying assumptions to find (a) the assumed complete break of both inlet and outlet pipes will completely drain the reactor vessel in less than 1 minute and (b) the ECCS coolant flow can probably remove the decay heat as long as there is a continuous source of cooling water and pumping power.

\section{Conclusions}

At the request of INP, ANL personnel have performed calculations for INP's VVR-K reactor during its intended initial operation with LEU fuel. These calculations include nuclear characteristics, steady-state operation, and various transients. The various cores (i.e., fresh LEU core at Cycle 1 plus Be reflected cores at Cycles 4, 10,12, and 15) satisfy the stated steady-state limits for peak cladding temperature and minimum ONBR. The four postulated transients (shim rod withdrawal, primary pump seizure, loss of offsite electric supply, and impact of experiments) for which detailed analyses were performed are 
automatically terminated by safety systems before there can be any cladding damage. A scoping analysis of loss of coolant indicates that the vessel will completely drain in less than 1 minute but that decay heat can be removed from the fuel as long as there is a continuous source of cooling water and pumping power. These calculations have been performed independently from those being performed by INP and serve as one step in the verification process.

\section{References}

1. F. Arinkin, "SAR Descriptive Sections", Deliverable 15.2 under ANL-issued Work Order 7J-001410015, Institute of Nuclear Physics, Almaty, Kazakhstan (June 2014).

2. Safety Analysis Report for Research Reactor VVR-K, multiple institutes (1996).

3. D. Nakipov, "Steady-State and Accident Analysis for the VVR-K Reactor", Deliverable 15.3 under ANL-issued Work Order 7J-00141-0015, Institute of Nuclear Physics, Almaty, Kazakhstan (August 2015).

4. X-5 Monte Carlo Team, MCNP - A General Monte Carlo N-Particle Transport Code, Version 5, LAUR-03-1987, Los Alamos National Laboratory, Los Alamos, New Mexico (2003).

5. John G. Stevens, The REBUS-MCNP Linkage, ANL/RERTR/TM-08-04, Argonne National Laboratory, Lemont, Illinois (April 2008).

6. N.A. Hanan, A.P. Olson, R.B. Pond, and J.E. Matos, "A Monte Carlo Burnup Code Linking MCNP and REBUS", Proceedings of the 20th International Meeting on Reduced Enrichment for Research and Test Reactors RERTR 1998 (http://www.rertr.anl.gov/), São Paulo, Brazil, (October 18-23, 1998).

7. RELAP5-3D Code Development Team, RELAP5-3D Code Manual, INEEL-EXT-98-00834 (Volumes I through V), Idaho National Laboratory, Idaho Falls, Idaho (Revision 4.0, June 2012).

8. Arne P. Olson and M. Kalimullah, A Users Guide to the PLTEMP/ANL V4.1 Code, ANL/RERTR/TM11-22, Argonne National Laboratory, Lemont, Illinois (May 22, 2011).

9. S. A. Sokolov et al., Technical Project with LEU Fuel Assemblies: Work for Stage 9, TVEL Fuel Company of Rosatom, Moscow, Russia, Table 3.1 (2010).

10. S. Koltochnik, "Updated List of the Initiating Events to be Considered", email to N. Hanan (ANL), Institute of Nuclear Physics, Almaty, Kazakhstan (February 14, 2015).

11. A. P. Olson, A users Guide to the PARET/ANL Code (Version 7.5), ANL/RERTR/TM-11-38, Argonne National Laboratory, Lemont, Illinois, (August 14, 2012).

12. M. Ragheb, "Decay Heat Generation in Fission Reactors", Safety Analysis of Nuclear Reactor Systems (Chapter 8 of lecture notes for Course NPRE-457, University of Illinois, UrbanaChampaign, Illinois), posted by author at http://www.mragheb.com/NPRE\%20457\%20CSE\%20462\%20Safety\%20Analysis\%20of\%20Nucle ar\%20Reactor\%20Systems/index.htm (October 15, 2014). 
For Verification Purposes Only 



\section{Argonne}

Nuclear Engineering Division

Argonne National Laboratory

9700 South Cass Avenue, BIdg. 208

Argonne, IL 60439

www.anl.gov 